6. HISTORIA DEL DERECHO CANÓNICO 

Revista de Estudios Histórico-Jurídicos

[Sección Historia del Derecho Canónico]

XXXII (Valparaíso, Chile, 2010)

[pp. 421 - 450]

\title{
La Participación de los obispos del Perú en la CODIFICACIÓN DEL DERECHO CANÓNICO DE 1917: LOS "POSTULATA EPISCOPORUM"
}

\author{
[Participation of Peruvian Bishops in 1917 Canon Law Codification:
} "postulata episcoporum"]

\section{Carlos Salinas Araneda*}

Pontificia Universidad Católica de Valparaíso ${ }^{* *}$

\begin{abstract}
RESUMEN
La redacción del primer Código de Derecho Canónico que tuvo la Iglesia latina fue ordenada por el papa san Pío X en 1904. La tarea codificadora, empero, no fue obra de un grupo cerrado de expertos, sino que tuvo en cuenta el parecer del episcopado latino, el que fue consultado en dos momentos diferentes; en ambos fueron consultados los obispos peruanos. En este trabajo se estudia, a partir de la documentación guardada en el Archivo Secreto Vaticano, el aporte de los obispos peruanos en la primera consulta, realizada en 1904.

Palabras clave: Codificación canónica - Código de Derecho Canónico de 1917 - Obispos peruanos - Postulata episcoporum.
\end{abstract}

\begin{abstract}
In 1904, Pope Saint Pius X ordered the first draft for the Code of Canon Law that the Latin Church ever had. The codification task, however, was not only the work of a closed group of experts, but it also took into account the considerations of the Latin episcopate that was consulted in two different occasions and, in both times, the Peruvian bishops were consulted. Based on the documents kept at the Vatican Secret Archives, this article studies the contribution of the Peruvian bishops in their first request in 1904.

Keywords: Canonic codification - 1917 Code of Canon Law - Peruvian bishops - Postulata episcoporum.
\end{abstract}

* Profesor titular de Historia del Derecho y de Derecho Canónico en la Facultad de Derecho de la Pontificia Universidad Católica de Valparaíso. Dirección postal: Avenida Brasil 2950, Valparaíso, Chile. Dirección electrónica: csalinas@ucv.cl. Este trabajo forma parte de la investigación FONDECYT 1095074 de la que el autor es investigador responsable.

** Abreviaturas: $A$ AS. = Acta Apostolicae Sedis (Ciudad del Vaticano); ASS. = Acta Sanctae Sedis (Roma); ASV. = Archivo Secreto Vaticano (Ciudad del Vaticano); ASV. CIC 1917 = Archivo Secreto Vaticano (Ciudad del Vaticano) "Fondo Commissione (Pontificia) per la codificazione del Diritto canonico", Índice 1164; CIC 1917 = Código de Derecho Canónico de 1917; EAC. = El amigo del clero. Boletín eclesiástico de la arquidiócesis $(\mathrm{Lima}) ;$ Fontes = GASPARRI, Petrus (editor), Codicis Iuris Canonici. Fontes (Typis Polyglottis Vaticanis, 1933-1962). 


\section{UN TEMA HASTA AHORA POCO O CASI NADA CONOCIDO}

\section{La necesidad de fijar el Derecho canónico.}

El Derecho canónico, esto es, el Derecho de la Iglesia católica, constituye en ella un elemento esencial, razón por la cual las normas en la Iglesia han existido desde los primeros momentos de su historia en una evolución que ya alcanza los dos mil años. Durante el primer milenio dichas normas se recogieron en colecciones canónicas, de diversa naturaleza y contenido ${ }^{1}$, que fueron sustituidas en el segundo milenio por el Corpus Iuris Canonici, un amplio texto compuesto de cinco colecciones, la primera de las cuales fue el Decreto de Graciano (1140) seguido por las Decretales de Gregorio IX (1234), el más importante de los textos canónicos de dicho Corpus. Lo integraban, además, el Liber sextus de Bonifacio VIII (1298); las Clementinas, una colección ordenada por el Papa Clemente V y promulgada en 1317 por su sucesor, Juan XXII; las Extravagantes comunes y las Extravagantes de Juan XXII, colecciones menores elaboradas en el siglo XVI por el jurista parisino Jean Chapius ${ }^{2}$.

En la medida que fue pasando el tiempo, junto al Corpus se fue elaborando una abundante legislación complementaria que venía a satisfacer las necesidades que iban originando las nuevas realidades históricas que la Iglesia debía enfrentar, de manera que, en pleno siglo XIX, el conocimiento del Derecho de la Iglesia se hacía en extremo difícil, con la consecuente dificultad en su aplicación y la secuela de inobservancia que un tal fenómeno trae consigo. Un postulatum de once obispos franceses durante el Concilio Vaticano I (1869-1870) resulta en este sentido revelador ${ }^{3}$ " Es una cosa muy evidente y reconocida desde hace mucho tiempo por todos y por todas partes reclamada que es necesario y muy urgente un examen y una refundición del Derecho canónico. Porque, como consecuencia de los grandes y numerosos cambios sobrevenidos en las circunstancias y en la sociedad humana, muchas leyes han llegado a ser inútiles o inaplicables o muy difíciles de observar. Se duda, incluso, si numerosos cánones se encuentran aún en vigencia. En fin, a lo largo de tantos siglos el número de leyes eclesiásticas ha crecido de tal manera y ellas forman un tal cúmulo de colecciones que, en cierto

\footnotetext{
${ }^{1}$ Para una historia del Derecho canónico en el primer milenio puede verse: GarCía y García, Antonio, Historia del Derecho canónico, I: El primer milenio (Salamanca, 1967), con abundante bibliografía hasta la fecha de su edición. Más recientemente, con la bibliografía posterior, EDWIN Ferme, Brian, Introduzione alla storia delle fonti del Diritto canonico, I: Il Diritto antico fino al Decretum di Graciano (Roma, Pontificia Università Lateranense, 1998).

${ }^{2}$ El Corpus Iuris Canonici fue objeto de una edición oficial a cargo de una comisión romana cuyos miembros fueron llamados "correctores romanos". Fue instituida por san Pío V (1566-1572) y la edición de los correctores romanos publicada por Gregorio XIII (1572-1585) en 1582. Esta edición no recoge la denominación de Corpus Iuris Canonici, la que sí aparece en la edición de Lyon de 1671 y en las posteriores. La edición hoy utilizada habitualmente es la de A. E. Friedberg (Lipsiae, 1879, reimpresión Graz, 1959). Con posterioridad el Corpus fue complementado incorporándose en diversas épocas otros elementos, algunos de los cuales sólo en ediciones privadas.

${ }^{3}$ Mansi, J. D., Sacrorum conciliorum nova et amplissima collectio, Sacrosancti oecumenici Concilii Vaticani, 53, col. 341-342.
} 
sentido, podemos decir que estamos aplastados por las leyes. A consecuencia de esto el estudio del Derecho canónico está lleno de dificultades inextricables y casi infinitas; el más vasto campo está abierto a las controversias y procesos; las conciencias están oprimidas por miles de angustias y empujadas al menosprecio de la ley". No fueron los únicos, pues otros obispos se manifestaron en el mismo sentido ${ }^{4} \mathrm{y}$, si bien las soluciones que sugerían no fueron coincidentes, algunas de ellas se situaban en la línea de la codificación del Derecho canónico ${ }^{5}$, es decir, aplicar al Derecho de la Iglesia la nueva modalidad de fijar el Derecho que se había desarrollado en el Derecho de los Estados a partir del siglo XVII, la codificación iusracionalista ${ }^{6}$ que, cuando este debate ocurría en el seno del Derecho canónico, ya se había materializado en numerosos códigos, incluso en Hispanoamérica ${ }^{7}$.

\section{La codificación del Derecho canónico.}

La tarea de elaborar un Codex Iuris Canonici que sustituyera al Corpus fue iniciada por el papa san Pío X (1903-1914) a poco de haber iniciado su pontificado en los albores del siglo XX. Lo hizo mediante el motu proprio Arduum sane munus, de 19 de marzo de $1904^{8}$, mediante el cual creó una comisión pontificia

${ }^{4}$ Además de la intervención señalada en la nota anterior, fueron los postulados suscritos por 37 obispos napolitanos, ibíd., col. 378-456, esp. 449-450; 15 obispos alemanes, ibíd., col. 352-378, esp. 355; el episcopado belga, ibíd., col. 456-461, esp. 460-461; 33 padres de diversas naciones, ibíd., col. 478-479; los obispos de las provincias eclesiásticas de Québec y Halifax, ibíd., col. 467; y un grupo de prelados de Italia central, ibíd., col. 552-553.

${ }^{5}$ En relación con el debate antecedente a la codificación canónica, puede consultarse: ANÓNIMO, Pio Xe la codificazione del Diritto canonico, en Il Contencioso Ecclesiastico, 5 (1904), pp. 66-68; Bersani, F., Le fonti del Diritto canonico prima della codificazione, en Rivista di Diritto Ecclesiastico, 10 (1917), pp. 23-41; Boudinhon, A., De la codification du Droit canonique, en Le Canoniste Contemporain, 27 (1904), pp. 641-650; 28 (1905), pp. 18-23, 76-83, 139-149, 207-215, 302-309, 473-481, 563-568; CALISSE, C., La codificazione del Diritto canonico, en Rivista Internazionale di Scienze Sociali, 35 (1904), pp. 346-365; LAMER, H., Zur Codification des canonischen Rechts (Freiburg Br., 1899), pp. 63-96; 212-213; RufinI, Francesco, La codificazione del Diritto ecclesiastico, en AA. VV., Studi di Diritto in onore di Vittorio Scialoja (Milano, 1905), II, pp. 353-391; VILLIEN, A., Les reformes du Droit canonique et les "postulata" du concile du Vaticain, en Le Canoniste contemporaine, 29 (1906), pp. 65-74, 209-221, 369-384, 449-463, 554-564, 652-659, 712-717; 30 (1907), pp. 74-83, 137-147, 220-228, 273-283; 31 (1908), pp. 16-23, 207-219, 364-376.

${ }^{6}$ Una reciente y completa síntesis sobre la codificación en: GUZMÁN BRITO, Alejandro, El origen y desarrollo de la idea de codificación del Derecho, en GUZMÁN BRITO, Alejandro (editor), El Código Civil de Chile (1855-2005). Trabajos expuestos en el Congreso internacional celebrado para conmemorar su promulgación (Santiago, 3-6 de octubre de 2005) (Santiago LexisNexis, 2007), pp. 43-99.

${ }^{7}$ Para la codificación civil en Hispanoamérica el más completo y actual trabajo es: GuZMÁN BRITO, Alejandro, La codificación civil en Iberoamérica. Siglos XIX y XX (Santiago, Editorial Jurídica de Chile, 2000), del que hay una segunda edición notablemente ampliada (Cizur Menor, Navarra, Thomson, Aranzadi, The Global Law Colection, 2006).

${ }^{8}$ Publicado en ASS. 36 (1903-1904), pp. 549-551. El motu proprio lleva la fecha 14 de abril de 1904, pero parece que se trata de un error de imprenta, pues en la carta circular Pergratum mihi, fechada el 25 de marzo de 1904, hay una referencia expresa al motu proprio Arduum sane munus. Son de esta opinión, Llobell, Joaquín - De León, Enrique - NAVARRETe, Jesús, Il libro "De processibus" nella codificazione del 1917. Studi e documenti (Milano, Giuffré, 1999), 
encargada de asumir la codificación del Derecho de la Iglesia 9 .

La elaboración del código, sin embargo, no fue una tarea de un grupo cerrado de iniciados, sino que, contando con el trabajo de un número importante de expertos bajo la dirección de Pedro Gasparri ${ }^{10}$, el mismo motu proprio dispuso la intervención de todo el episcopado latino ${ }^{11}$. De esta manera, una de las principales características del proceso de codificación del Derecho canónico de 1917 consistió en la participación, promovida por la misma Santa Sede, del episcopado en la elaboración del Codex. Dicha participación, por cierto, la primera realizada históricamente por la Iglesia al emprender la tarea de elaborar un cuerpo legislativo universal, se articuló en dos grandes momentos: el primero, al inicio de los trabajos de codificación, a través de los Postulata episcoporum; el segundo, en pleno proceso codificador, cuando se estaba llegando a la fase conclusiva del mismo, a través de las Animadversiones episcoporum. De ambos es el primero el que ahora me interesa.

La primera de dichas consultas fue llevada a la práctica mediante la circular Pergratum mihi, de la Secretaría de Estado, de fecha 25 de marzo de 1904, enviada a todos los metropolitanos ${ }^{12}$. En ella se disponía que los arzobispos, después de haber oído a sus sufragáneos y otros ordinarios que debían estar presente en el concilio provincial, debían hacer llegar a la Santa Sede, dentro de los cuatro meses siguientes, en pocas palabras, las principales modificaciones y correcciones que debían hacerse al Derecho canónico en vigor. En la misma circular se indicaba que era deseo formal del papa ver a todo el episcopado concurrir y tomar parte activa en un asunto que interesaba en grado máximo el bien y utilidad de toda la Iglesia católica ${ }^{13}$.

En la misma circular se comunicaba a los obispos que, por decisión del Santo Padre, los obispos de cada nación tenían la facultad de escoger y enviar a Roma, a su costo, uno o dos especialistas en Derecho canónico o teología, que pudiesen

I, p. 34 n. 30. Para una historia de la codificación canónica de 1917, por todos puede verse: FANTAPPIE, Carlo, Chiesa romana e modernità giuridica, I: L'edificazione del sistema canonistico (1563-1903); II: Il Codex Iuris Canonici (1917) (Milano, Giuffrè, Per la storia del pensiero giuridico moderno 76, 2008), con bibliografía actualizada.

${ }^{9}$ La nómina de sus integrantes en ASS. 36 (1903-1904), p. 551.

${ }^{10}$ Antiguo profesor en el Instituto católico de Paris, entonces arzobispo titular de Cesarea y secretario de la $S$. Congregación de asuntos eclesiásticos extraordinarios, a quien se le nombró al mismo tiempo presidente de la Comisión de consultores. Posteriormente sería hecho cardenal.

${ }^{11}$ En la decisión cuarta el papa manifestaba su deseo de que todo el episcopado, conformándose a las reglas que serían dadas en tiempo oportuno, colaboraran y concurrieran a esta obra tan importante: "IV. Volumus autem universum episcopatum, iuxta normas opportune tradendas, in gravissimum hoc opus conspirare atque concurrere".

${ }^{12}$ ASS. 36 (1903-1904), pp. 603-604.

${ }^{13}$ Como se ha observado, se solicitó la colaboración del episcopado para que los consultores, con frecuencia hombres más bien teóricos, fuesen iluminados por las condiciones de vida particular en los diferentes países; la consulta era necesaria para asegurar que el nuevo código tuviese un carácter eminentemente práctico y para que, gracias a las sugerencias de los obispos, se eliminasen todas las imperfecciones del Derecho vigente, introduciéndole al mismo tiempo las reformas necesarias. Vetulani, A., Codex Juris Canonici, en Dictionnaire de Droit Canonique (Paris, 1942), III, col. 920. 
formar parte del grupo de consultores; si preferían escoger uno de los que ya habían sido nombrados consultores por los cardenales, podían encargarles que los representara para someter a discusión y defender sus proposiciones en las reuniones de los consultores; incluso, podían nombrar a alguno de su nación que, residiendo fuera de Roma, pudiese, por correspondencia, aportar de alguna manera a los consultores el apoyo de su colaboración.

La respuesta de los obispos del mundo latino fue amplia, contándose entre ellas la de numerosos obispos latinoamericanos, incluidos los peruanos. Se calcula en aproximadamente cinco mil el número de personas que fueron consultadas por lo que, no sin razón, se ha dicho que el trabajo de consulta a los obispos fue como un concilio ecuménico por correspondencia.

El numeroso material reunido fue sistematizado en un volumen que permaneció inédito, bajo la dirección del consultor Bernardino Klumper, con el título Postulata Episcoporum in ordine digesta ${ }^{14}$. Posteriormente se agregó un segundo volumen, más breve que el anterior, con sólo 68 páginas, impreso en 1908 con el título Appendix ad Postulata Episcoporum, reproducido igualmente por Bernardino Klumper ${ }^{15}$ en el que se recogen, probablemente, las respuestas llegadas con retraso, cuando el primero de estos volúmenes ya estaba en prensa. Ninguno de los dos volúmenes llegó a empastarse y su circulación quedó estrictamente restringida a los consultores, de manera que no fueron conocidos fuera de ellos. Preciso es tener presente, sin embargo, que no todos los postulata fueron recogidos por Klumper, si bien la mayoría lo fue; pero de estos, el consultor fue incorporando lo que consideraba de utilidad o cambió de colocación las sugerencias iniciales, por lo que la consulta a los documentos originales se hace indispensable para poder conocer con precisión lo sugerido por los obispos ${ }^{16}$.

Como ha sido puesto de relieve ${ }^{17}$, estos postulata reflejan el sentir del episcopado mundial en lo que se refiere a la codificación y permiten conocer cuales eran las preocupaciones y los problemas que interesaban al episcopado mundial a los inicios del siglo XX, no sólo de orden jurídico, sino también eclesiológico, disciplinar, pastoral, etc.; desde esta perspectiva, los postulata constituyen una útil manera de aproximarse a las realidades de las iglesias locales de la época a partir de unos protagonistas tan directos como son los obispos de cada una de ellas. En ellos se solicitan soluciones que, en no pocos casos, sólo fueron adoptadas por el Concilio Vaticano II y el Código de Derecho Canónico de $1983^{18}$.

\footnotetext{
${ }^{14}$ Codex Iuris Canonici/ Postulata Episcoporum/ in ordinem digesta/ a/ Rmo. P. Bernardino Klumper O. F. M./ Consultore/ Romael Typis Vaticanis/ 1905/ 283 pp. ASV. CIC 1917, caja 4. En adelante: Postulata.

${ }^{15}$ ASV. CIC 1917, caja 6.

${ }^{16} \mathrm{Al}$ no estar todavía generalizado el uso de la máquina de escribir, la mayoría de los postulata son manuscritos, lo que dificulta su lectura, a lo que hay que agregar el que ellos están escritos en diversas lenguas, porque no todos los obispos usaron el latín para sus respuestas, si bien un número importante usó la lengua oficial de la Iglesia.

${ }^{17}$ Llobell, Joaquín - De León, Enrique - Navarrete, Jesús, cit. (n. 8), pp. 47-48.

${ }^{18}$ Otra circular, esta vez de 6 de abril de 1904, atribuible al secretario de la Comisión, Pedro Gasparri, fue dirigida a los rectores de las universidades católicas para pedirles el concurso "en esta empresa importante y dificil”. Circular Perlegisti, en ASS. 37 (1904-1905), pp. 130-131.
} 


\section{LOS PROTAGONISTAS PERUANOS}

\section{El arzobispo y los obispos.}

En marzo de 1904, cuando se hace la consulta al episcopado, la provincia eclesiástica de Perú estaba integrada por el arzobispado de Lima y los obispados de Arequipa, Chachapoyas, Cuzco, Guamanga o Ayacucho, Huánuco, Huaraz, Puno y Trujillo. Era arzobispo de Lima, Manuel Tovar y Chamorro ${ }^{19}$, promovido a la sede arquidiocesana de Lima el 22 de agosto de 1898. Obispo de Arequipa era Manuel Segundo Ballón ${ }^{20}$, nombrado el 25 de agosto de 1898, cargo al que renunció en 1906. El obispado de Chachapoyas al momento de la consulta estaba vacante, pero por esos mismos meses, era nombrado al frente de la diócesis José Santiago Irala, ofm., quien fue elegido para dirigirla el 8 de junio de 1904, razón por la que es muy probable que, dado el plazo fijado por Roma, no hubiese sido consultado o no alcanzó a responder al arzobispo ${ }^{21}$. Obispo de Cuzco era Juan Antonio Falcón Iturrizaga, promovido a la sede de Cuzco el 19 de enero de $1893^{22}$. Obispo de Guamanga o Ayacucho era Fidel Olivas Escudero ${ }^{23}$, elegido para la diócesis de Guamanga el 19 de abril de 1900, permaneciendo al frente de ella hasta su muerte ocurrida el 12 de abril de 1935, a la edad de 86 años. Obispo de Huánuco era Pedro Pablo Drinot y Piérola ${ }^{24}$, ss.cc., elegido obispo de Huánuco el 8 de junio de 1904 y consagrado el 24 de agosto del mismo año, permaneciendo al frente de la diócesis hasta el 21 de octubre de 1920, por renuncia a la misma; dada la fecha de su elección y consagración, es probable que no haya sido consultado considerando el plazo puesto por la Santa Sede para la consulta. Obispo de Huaraz era Mariano Holguín ${ }^{25}$, ofm., elegido obispo de Huaraz el 2 de julio de 1904, permaneciendo al frente de la diócesis hasta el 20 de mayo de 1906, fecha en que fue trasladado al obispado de Arequipa. En atención a la fecha de su nombramiento y a los plazos establecidos por la Santa Sede es probable que tampoco haya sido consultado. Obispo de Puno era Ismael Puirredon ${ }^{26}$, elegido para el obispado de Puno el 14 de febrero de 1889, permaneciendo al frente de la diócesis hasta el 29 de noviembre de 1909, retirándose por renuncia. Obispo de Trujillo era Manuel Santiago Medina Bañón ${ }^{27}$, elegido para el obispado de

\footnotetext{
${ }^{19}$ Nació en Sayan en 1844. Falleció siendo arzobispo de Lima, el 25 mayo 1907.

${ }^{20}$ Nació en Tiabaya, diócesis de Arequipa, el 31 de mayo de 1854 . Fue obispo de Arequipa y falleció en Lima, siendo obispo auxiliar de la arquidiócesis, en 1923.

${ }^{21}$ Nació en Huanta, el 30 diciembre 1856. Falleció el 28 julio 1939 como obispo emérito de Chachapoyas.

${ }^{22}$ Nació en Lima el 3 enero 1832. Falleció el 1 mayo 1909, siendo obispo de Cuzco.

${ }^{23}$ Nació en Pomabamba, arquidiócesis de Lima, el 3 enero 1849. Murió siendo obispo de Ayacucho el 12 abril 1935 a la edad de 86 años.

${ }^{24}$ Nació en el Callao, arquidiócesis de Lima, el 29 noviembre 1859. Falleció el 11 septiembre 1935 como obispo emérito de Huanuco, a los 75 años de edad.

${ }^{25} \mathrm{Nació}$ en Arequipa el 5 octubre 1860. Falleció como arzobispo de Arequipa, el 24 diciembre 1945 , a la edad de 85 años.

${ }^{26}$ Nació en Lima el 22 junio 1855. Murió en Lima, como obispo emérito de Puno el 11 noviembre 1916 a la edad de 61 años.

${ }^{27}$ Nació en Lima el 30 enero 1836 (otros dicen que el 30 diciembre 1835). Falleció en Lima
} 
Trujillo el 14 de febrero de 1889, pero desde 1901 residía en Lima por razones de salud, por lo que en 1904 era administrador apostólico el obispo de Puno, Ismael Puirredón.

Conforme a lo anterior, a la fecha de esta primera consulta romana estaban provistos el arzobispado de Lima y los obispados de Arequipa, Cuzco, Guamanga o Ayacucho, y Puno. Se nombraban por esos mismos días los obispos de Chachapoyas, Huánuco, Huaraz. Y estaba vacante el obispado de Trujillo del que era administrador apostólico el obispo de Puno.

\section{La respuesta del arzobispo de Lima.}

La carta circular Pergratum mihi enviada por Roma a los obispos lleva por fecha 25 de marzo de 1904, y fue enviada al arzobispo de Lima por medio del delegado apostólico para Perú, Ecuador y Bolivia, Alejandro Bavona, en carta del 17 de mayo de 1904 junto con el motu proprio De Ecclesiae legibus in unum redigendis ${ }^{28}$. En la misma carta el delegado apostólico le avisaba que los mismos documentos habían sido enviados por él a los otros obispos del Perú, y le hacía presente "la trascendencia de la obra que la Santa Sede va a emprender", estando cierto que el arzobispo, "con el celo que le distingue, procurará de llevar a efecto lo que en la mencionada carta se indica”. Dos días después, el 19 de mayo, respondía el arzobispo de Lima la carta del delegado apostólico ${ }^{29}$, manifestándole que cumpliría fielmente las disposiciones de la Santa Sede, "a fin de cooperar en mi humilde esfera, al grandioso y trascendental proyecto que el Sumo Pontífice se propone realizar en bien de la Iglesia".

El día anterior, el 18 de mayo de 1904, adelantándose a la respuesta del arzobispo y, probablemente, también a la de los obispos, el delegado apostólica avisaba al cardenal Secretario de Estado ${ }^{30}$ haber recibido la circular que de inmediato había distribuido a los obispos, quienes habían recibido "con aplauso general” la noticia de la codificación del Derecho canónico, por lo que manifestaba su seguridad de "que ellos harán de todo por secundar los altos propósitos de Su Santidad", para lo cual había "interesado al arzobispo de Lima” que era quien tenía que comunicarla a los obispos de su provincia eclesiástica.

Si el papa deseaba que las respuestas fueran enviadas a Roma dentro de los cuatro meses siguientes, los obispos tenían hasta el mes de septiembre para hacerlo. La respuesta de Lima ${ }^{31}$, sin embargo, lleva por fecha el 3 de octubre de 1904, por lo que, al término de la misma, el arzobispo pedía excusas por "la demora de algunos días en la expedición de este informe”, lo que se debía al retraso con que los obispos sufragáneos habían respondido a su invitación, porque, si bien inmediatamente después de haberla recibido, el arzobispo se había dirigido a los obispos sufragáneos y demás ordinarios del Perú, "para dar exacto cumplimiento al

el 19 marzo 1907, a los 72 años de edad.

${ }^{28}$ EAC. 13 (26 mayo 1904), 469, p. 286. La carta circular Pergratum mihi, ibíd., pp. 286-

287; el motu proprio De Ecclesiae legibus in unum redigendis, ibíd., pp. 288-289.

${ }^{29}$ EAC. 13 (26 mayo 1904), 469, pp. 289-290.

${ }^{30}$ ASV. CIC 1917, caja 1.

${ }^{31}$ ASV. CIC 1917, caja 96. Se transcribe al final de este artículo. 
mandato de la Santa Sede", "las distancias y por hallarse en visita pastoral algunos de los prelados, retardaron sus respuestas".

Las respuestas recibidas, sin embargo, se limitaron a acusar recibo de la circular que les había enviado el arzobispo, indicando que "oportunamente manifestarían los puntos que, a su juicio, merecían ser modificados en la legislación de la Iglesia”. El único que, en su respuesta, se refirió al tema de fondo de la circular fue el obispo de Puno, Ismael Puirredón, que a la sazón era, además, administrador apostólico de Trujillo, quien, sin embargo, sólo se limitó a expresar la conveniencia de que hubiere un código procesal uniforme para todas las curias eclesiásticas. Los "puntos" que sugerirían a futuro los demás obispos no llegaron por lo que, "no habiendo recibido ninguna comunicación posterior", el arzobispo procedió a reunir al consejo de administración diocesana para escuchar sus opiniones y poder informar a Roma.

En la circular enviada desde Roma, como hemos visto, se ofrecía a los obispos la posibilidad de escoger uno de los consultores que ya habían sido nombrados por los cardenales y encargarles que los representara para someter a discusión y defender sus proposiciones en las reuniones de los consultores. Acogiendo esta posibilidad, "por el voto unánime" de los obispos fue designado como consultor de la provincia eclesiástica el padre Francisco Javier Wernz ${ }^{32}$. El mismo día de la respuesta, y previo a la misma, el arzobispo Tobar había emitido un decreto ${ }^{33}$ por el que nombraba al padre Wernz "como consultor de esta provincia eclesiástica... para los fines a que se refiere el Motu proprio ${ }^{34}$ del Sumo Pontífice acerca de la codificación del Derecho canónico".

\section{LOS “POSTUlATA” DE LOS OBISPOS PERUANOS}

\section{La propuesta del obispo de Puno, Ismael Puirredón.}

El único de los obispos sufragáneos consultados que respondió a la invitación

${ }^{32}$ Francisco Javier Wernz nació en Rottweil, Wurtemberg, el 4 diciembre 1842. En 1857 entró en la Compañía de Jesús, debiendo dejar Alemania por las proscripciones antijesuíticas de la Kulturkampf, dirigiéndose a Austria donde enseñó letras en el colegio de Feldkirch; pasó después a Exaten, en Holanda, y de allí a Inglaterra donde amplió estudios de Derecho canónico en Ditton Hall. Pasó a enseñar en St. Beuno (Galles) de donde, en 1882, se le llamó a Roma para desempeñar la cátedra de Derecho canónico en la Universidad Gregoriana, de la que llegó a ser rector en 1904 . Fue elegido $25^{\circ}$ prepósito general de la Compañía de Jesús en 1906. Falleció en Roma el 19 agosto 1914. Altamente estimado por su claridad, su profundidad, prudente moderación e inconcusa justicia, desde 1886 fue consultor de las SS. Congregaciones del concilio, del santo oficio y de asuntos eclesiásticos extraordinarios; fue igualmente miembro de la comisión para la codificación del Derecho canónico desde los inicios del trabajo codificador. Su mayor fama, que ha alcanzado hasta nuestros días, se debió a su Jus decretalium, que publicó en seis volúmenes entre 1898 y 1914, por la ordenación dada a las materias, el desarrollo completo y erudito de cada una de ellas, la abundancia de información histórica, y el uso constante de la filosofía del Derecho y de las ciencias afines. No pocas de sus sugerencias y formulaciones quedaron plasmadas en el Código de Derecho Canónico de 1917.

${ }^{33}$ ASV. CIC 1917, caja 1

${ }^{34}$ Las palabras "Motu proprio" están subrayadas en el original. 
del arzobispo fue el obispo de Puno, Ismael Puirredón, que a la sazón era, además, administrador apostólico de Trujillo. Su propuesta, recogida en el informe del arzobispo, fue simple: que hubiera un código procesal uniforme para todas las curias eclesiásticas. Esta sugerencia fue asumida por el arzobispo de Lima y por la unanimidad de los miembros del consejo de administración diocesana a quien el arzobispo había consultado.

La sugerencia no agregaba mayores antecedentes acerca de la naturaleza del código procesal propuesto ni precisaba mayormente los contenidos del mismo, si bien, al parecer, se trataba de un texto diverso al Código de Derecho Canónico que se pretendía; de ser así, la propuesta, al proponer un segundo texto, se separaba de las pretensiones de la Santa Sede de reducir a un solo libro el Derecho de la Iglesia. En cuanto al contenido del mismo, la referencia era genérica pues se trataba de un código que debía regular los procedimientos a seguir en las curias eclesiásticas, sin precisar si se trataba de procedimientos judiciales o administrativos. Los acontecimientos posteriores, sin embargo, vendrían a aclarar este punto.

En efecto, algunos años después, en la asamblea episcopal del año 1915, asamblea trienal que celebraban los obispos del Perú en cumplimiento de una norma del Concilio Plenario de América Latina que así lo sugería ${ }^{35}$, los obispos adoptaron el siguiente acuerdo ${ }^{36}$ : "XI. Código procesal. Siendo necesario uniformar los procedimientos de las Curias en la tramitación de los juicios eclesiásticos, la asamblea acuerda: que se redacte un Código procesal, encargando de este trabajo a una comisión, que se compondrá del Ilmo. y Rvmo. Mons. Dr. D. Manuel S. Ballón 37, Dr. D. Mariano Aguilar y Dr. D. Eleodoro Romero" ${ }^{38}$. La referencia venía a aclarar el contenido del código que se pretendía, pues se trataba de un código que debía regular "la tramitación de los juicios eclesiásticos".

Preciso es tener presente, sin embargo, que los obispos peruanos tenían a su disposición normas procesales que podían satisfacer su deseo de uniformar la tramitación de los juicios eclesiásticos, toda vez que algunos años antes, en 1906, se habían publicado en Roma las actas del Concilio Plenario de América Latina ${ }^{39}$ que había abordado expresamente el tema de los juicios eclesiásticos, proporcionando normas expresas sobre el particular, tanto en lo referido a las causas matrimoniales ${ }^{40}$, como a las causas de los clérigos ${ }^{41}$, además de la suspensión ex informata conscientia ${ }^{42}$. Se trataba, pues, de un tema sobre el cual había normas expresas, si bien no constituían un completo código de procedimiento sobre el

${ }^{35}$ Concilio Plenario de América Latina, decretos 208 y 288. Se puede ver Instructio circa conventus episcoporum Americae Latinae, en Actas y decretos del Concilio Plenario de la América Latina celebrado en Roma el años del Señor de MDCCCCXCIX (1906, Ed. Facs., Librería Editrice Vaticana, Ciudad del Vaticano, 1999), pp. clxxxi-clxxxii.

${ }^{36}$ EAC. 24 (1 agosto 1915), 856, pp. 326-331.

${ }^{37}$ Obispo auxiliar de Lima.

${ }^{38}$ El autor de la idea original en 1904, el obispo Ismael Puirredón, fallecería en Lima al año siguiente, el 11 de noviembre de 1916.

${ }^{39}$ Véase antes nota 35.

${ }^{40}$ Decretos 937-964.

${ }^{41}$ Decretos 965-991.

${ }^{42}$ Decretos 992-993. 
particular, pues en ellas se abordaban los aspectos que los obispos consideraban los más importantes acerca de los cuales unificar la disciplina. Por otra parte, en 1915, año en que se produce el acuerdo de la asamblea de obispos peruanos, ellos ya había conocido el proyecto del Libro V del futuro Código de Derecho Canónico referido, precisamente, a los procesos ${ }^{43}$, el que les había sido enviado para sus observaciones por el cardenal Pedro Gasparri, presidente de la comisión codificadora, en carta del 15 de noviembre de 1914, carta en la que se les daba el plazo de cinco meses para enviar sus respuestas ${ }^{44}$. El proyecto contenía 773 cánones y en él se hacía una acaba regulación no sólo de los procesos canónicos, sino también de la parte orgánica de los tribunales eclesiásticos. La respuesta de los obispos peruanos a este proyecto se hizo casi un año después, en carta del 22 de noviembre de 1915 enviada por el arzobispo de Lima, a la que acompañaba las "ligeras observaciones" hechas por los obispos al referido proyecto ${ }^{45}$. Es decir, al momento del acuerdo de la asamblea episcopal de 1915, los obispos peruanos ya conocían la acabada regulación que se hacía de la materia procesal en el fututo código canónico.

En otras palabras, la existencia de normas ya vigentes sobre el particular, y la inminencia de otras cuya preparación estaba muy avanzada, hace pensar que el contenido de este Código procesal sugerido por el obispo de Puno en 1904 y reiterado por la asamblea de obispos peruanos en 1915, se refería a materias más bien administrativas de las curias diocesanas que probablemente no eran comprendidas en las normas generales ya vigentes o por entrar en vigencia. Dos años después, en la asamblea episcopal peruana de 1917, se lee el siguiente nuevo acuerdo 46: "I. Código procesal. Que terminada la redacción del Código procesal, la misma comisión nombrada en 1915, sin esperar la reunión de la asamblea próxima, proceda a su impresión y distribución en las diversas diócesis". Ello ocurría cuando el Código de Derecho Canónico ya era una realidad y de cuya promulgación daba cuenta, precisamente, el número siguiente de El amigo del clero ${ }^{47}$.

¿Qué pasó con este Código procesal? Desconozco si la publicación ordenada se llevó a efecto, pues no me ha sido posible obtener un ejemplar de este libro. Lo que es claro es que, a partir de la entrada en vigencia del Codex Iuris Canonici ${ }^{48}$ la materia orgánica y procesal de los tribunales eclesiásticos estaba claramente regulada, uniformando, así, los procedimientos de las curias en la tramitación de los juicios eclesiásticos.

\footnotetext{
${ }^{43}$ (Schema Codicis Iuris Canonici)/(Sub secreto pontificio)/Codex Iuris Canonicil cum notis/ Petri card. Gasparril Romae/ Typis Polyglottis Vaticanis/ MDCCCCXIV// Liber Quintus/ De iudiciis ecclesiasticis.

${ }^{44}$ El texto de la carta, en latín, en Llobel, Joaquín; DE LEÓn, Enrique; NaVArRete, Jesús, cit. (n. 8), pp. 841-842.

${ }^{45}$ ASV. CIC 1917, caja 60.

${ }^{46}$ EAC. 26 (1 octubre 1917), 908, pp. 479-489, esp. 479.

${ }^{47}$ EAC. 26 (15 octubre 1917), 909, pp. 495-503.

${ }^{48}$ El día de Pentecostés de 1918, es decir, el 19 de mayo de 1918.
} 


\section{Las propuestas del arzobispo de Lima.}

Después de haberse hecho eco de la propuesta del obispo Puirredón, el arzobispo hizo relación de las demás sugerencias que consideraba conveniente que se tomaran en cuenta en la elaboración del Codex Iuris Canonici. Como se verá, no fueron muchas, y a cada una de ellas dedico las próximas páginas, en el mismo orden en que fueron propuestas por el arzobispo.

a) Supresión de los impedimentos en tercer y cuarto grado de consanguinidad y afinidad para la validez del matrimonio. Al tiempo de la codificación, la consanguinidad en línea recta irritaba el matrimonio en cualquier grado usque in infinitum; lo hacía por Derecho natural, según muchos teólogos, en el primer grado; según otros lo hacía por Derecho natural en todos. Lo cierto es que, según Donoso ${ }^{49}$, nunca se había dispensado en esta línea. En línea colateral, en otro tiempo la nulidad alcanzaba hasta el séptimo grado -canónico- , limitándose al cuarto grado en el IV Concilio Lateranense (1215), por lo que para las personas que estaban emparentadas en quinto grado o en quinto con cuarto, tercero o segundo, no había impedimento, disciplina que era la vigente al momento de la codificación. La nulidad era por Derecho natural sólo en el primer grado, según muchos teólogos, aunque había quienes consideraban que el matrimonio en ese grado, si bien sería gravemente ilícito, no sería nulo atendido sólo el Derecho natural.

Hay que tener en cuenta, para la exacta comprensión de la sugerencia del arzobispo, que la forma de contar los grados de parentesco en Derecho canónico era a la sazón diversa a la romana, que era la que había asumido el Código Civil peruano, de manera que, conforme al Derecho de la Iglesia, quedaban impedidos de celebrar un válido matrimonio canónico por razones de parentesco, quienes podían celebrarlo civilmente. En efecto, el tercer grado canónico de parentesco por consanguinidad en línea colateral significaba que no podían celebrar matrimonio entre si los primos en segundo grado; y el cuarto impedía celebrar matrimonio entre si a los primos en tercer grado. De esta manera, la propuesta del arzobispo de Lima dejaba subsistente la prohibición de celebrar matrimonio canónico a los hermanos entre sí, a los tíos(as) con las sobrinas(os) y a los primos hermanos o en primer grado entre sí.

La afinidad lícita, por su parte, esto es, la que se originaba por cópula lícita, dirimía el matrimonio entre el varón y las consanguíneas de la mujer o el de ésta con los consanguíneos de aquél, y se extendía, al tiempo de la codificación, hasta el cuarto grado. Hasta el IV Concilio Lateranense (1215) se prolongaba hasta el séptimo grado, siendo reducido por dicha asamblea conciliar al cuarto grado, disciplina que, en materia de afinidad lícita, conservó el Concilio de Trento (15451563) y era la vigente al momento de la codificación. Disputaban los doctores si la afinidad ex copula conjugali dirimía el matrimonio por Derecho natural en el primer grado de línea recta, o sea, entre el padrastro y la entenada, o la suegra y el yerno, existiendo numerosos defensores tanto de la respuesta afirmativa como negativa. En la práctica los papas constantemente se habían negado de dispensar

${ }^{49}$ Donoso, Justo, Instituciones de Derecho canónico americano (Valparaíso, 1848-1849), II, pp. 158-159. 
en ese grado. En los restantes grados de la línea recta y en los de la línea colateral, se convenía generalmente que el impedimento era de Derecho eclesiástico.

Nuevamente es preciso hacer la misma prevención hecha en relación con la forma de contar los grados del parentesco colateral por consanguinidad, esto es, la diversa manera de contar entre el Derecho canónico y el Derecho civil, pues, al igual que sucedía con el parentesco por consanguinidad, se producía una diferencia entre el ordenamiento de la iglesia y el civil, impidiendo aquél celebrar matrimonios que éste permitía por razón de parentesco.

La propuesta del arzobispo se refería al parentesco en línea colateral, pues el de la línea recta irritaba el matrimonio usque in infinitum, y parece inspirada en la constitución Trans oceanum de León XIII (1878-1903), de 18 de abril de $1897^{50}$ que en su número X disponía que "los indios y negros pueden contraer matrimonio dentro del tercero y cuarto grado tanto de consanguinidad como de afinidad'. El tema, sin embargo, al menos en lo que se refiere al cuarto grado, ya había sido planteado en el Concilio Vaticano I (1869-1870) ocasión en la que varios epis$\operatorname{copados}^{51}$ habían solicitado la supresión del cuarto grado de consanguinidad. Se trataba de un tema conocido por el arzobispo, porque por los mismos días en los que se preparaba y enviaba su respuesta a Roma, se había empezado a publicar por entregas periódicas en El amigo del clero un artículo ${ }^{52}$, sin nombre de autor, analizando la codificación emprendida por el papa San Pío X, en una de cuyas entregas se presentaban algunas de las modificaciones solicitadas con ocasión del Concilio Vaticano $I^{53}$. En esta misma publicación aparecían también las propuestas formuladas en el mismo Concilio de dejar reducido el impedimento de afinidad ex copula illicita no más allá del primer grado ${ }^{54}$; y la afinidad lícita no extenderla más allá del primer grado ${ }^{55}$ o del segundo ${ }^{56}$ o del tercero ${ }^{57}$.

No fue el arzobispo de Lima el único en sugerir esta reducción, pues hubo otros episcopados que, en sus postulata a la codificación, se habían referido al

\footnotetext{
${ }^{50}$ Su texto en ASS. 29 (1896-1897), pp. 659-663. Su texto bilingüe en Retamal Fuentes, Fernando, Chilensia Pontificia. Monumenta Ecclesiae Chilensia (Santiago, Ediciones Universidad Católica de Chile, 2002), II, 2, pp. 808-817. Diversas situaciones referidas a la transmisión del evangelio en América fueron generando durante el período indiano que la Iglesia indiana obtuviera de Roma privilegios diversos cuyo uso e interpretación, con el tiempo, fueron generando no pocas dudas y conflictos de conciencia, por lo que el 18 de abril de 1897, León XIII emitió unas letras apostólicas en forma de Breve, llamadas Trans oceanum, mediante las cuales quedó claro y superado el grave problema de los privilegios para América Latina.

${ }^{51}$ El obispo de Nápoles, los obispos de Francia, Alemania, Bélgica, Québec y Halifac en Canadá, y los obispos de Italia central.

${ }^{52}$ La publicación de este artículo se inició en EAC. 13 (1 setiembre 1904), 483, pp. 487-488.

${ }^{53}$ AEC. 13 (6 octubre 1904), 488, pp. 554-556.

${ }^{54}$ Los obispos de Alemania, Bélgica, Québec, Italia central.

${ }^{55}$ Obispos de Francia.

${ }^{56}$ Obispos de Alemania.

${ }^{57}$ Obispo de Nápoles. Para las diversas propuestas que se hicieron en el Concilio Vaticano I acerca de los impedimentos matrimoniales de parentesco por consanguinidad y afinidad, puede verse Villien, A., Les reformes du Droit canonique et les postulata du Concile du Vatican, en Le Canoniste Contemporain, 338 (février 1906), pp. 65-74; 340 (avril 1906), pp. 209-221.
} 
tema. Alguno, como el arzobispo de Santiago de Chile ${ }^{58}$, se limitaba simplemente a sugerir que se estudiare la posibilidad de eliminar algunos grados como irritantes del matrimonio contraído por quienes estaban ligados por ellos, postulado que compartió con otros tres episcopados, en cuanto a disminuir los grados del impedimento de afinidad ${ }^{59}$, y con otros tres episcopados en lo referido a disminuir los grados del impedimento de consanguinidad ${ }^{60}$. Otros episcopados fueron más explícitos: en lo que se refiere a la consanguinidad, algunos episcopados estaban por reducir el impedimento al tercer ${ }^{61}$ y hasta el segundo grado ${ }^{62}$, suprimiendo el cuarto grado o dejarlo sólo como impedimento impediente ${ }^{63}$. Otros pedían que se concediese a los obispos facultad para dispensar en algunos grados, sin especificar cuáles $^{64}$, o en tercer grado ${ }^{65}$. Y hubo quien, de conservarse el impedimento hasta el cuarto grado, pedía que se computase conforme a las reglas del Derecho civil ${ }^{66}$.

En cuanto a la afinidad lícita, fueron igualmente diversas las sugerencias: el mayor número estuvo por restringirla no existiendo, empero, unidad de criterio en cuanto a los grados, pues las propuestas iban de restringirlo al tercero ${ }^{67}$, al segundo $^{68} \mathrm{e}$, incluso, al primer grado ${ }^{69}$; o que se diese a los obispos la facultad de

${ }^{58}$ Salinas Araneda, Carlos, El primer aporte de los obispos chilenos a la codificación del Derecho canónico de 1917: los "postulata episcoporum" acerca del matrimonio, en Historia, 41 (julio-diciembre 2008) 2, pp. 433-436.

${ }^{59}$ Los padres de la provincia longobarda (Italia) y los arzobispos de Montevideo (Uruguay) y de Columbus (Canadá), en Postulata, cit. (n. 14), p. 165.

${ }^{60}$ Los arzobispos de Montevideo (Uruguay), de Columbus y de Québec (Canadá), ibíd., p. 165 . 169.

${ }^{61}$ Los padres de la provincia de Ruan (Francia) y de Halifax (Canadá), ibíd, pp. 167,

${ }^{62} \mathrm{El}$ vicario capitular de la diócesis de Marsorum (Avezzano, Italia) y otros 19 episcopados, ibíd, p. 164. El arzobispo de Alger (Argelia), y otros seis episcopados, ibíd, p. 163. Los padres de la provincia de Eger (Hungría) y otros ocho episcopados, ibíd., p. 168. Los padres de la provincia de Quito (Ecuador), ibíd., p. 170. Otros siete episcopados, ibíd., p. 175. Los obispos de Apulia (Italia), ibíd., p. 177.

${ }^{63}$ Los obispos de las diócesis de Arras (Francia) y de San Alberto (Canadá), ibíd., pp. 170,168 .

${ }^{64}$ Los obispos de la región de Calabria (Italia), ibíd., p. 170.

${ }^{65}$ Los padres de las provincias de Poznan (Polonia), de Salzburgo (Austria) y de Tarragona (España), y los obispos de la región Beneventana (Italia), ibíd., pp. 176, 178.

${ }^{66}$ El obispo de Kandi (actualmente República de Benin), ibíd., p. 174.

${ }^{67}$ Los obispos de Jaffa (Israel) y los padres de la provincia de Cincinnati (USA), ibíd., p. 174; los obispos de la región Beneventana (Italia), ibíd., p. 178; los padres de la provincia de Halifax (Canadá), ibíd., p. 169; los padres de la provincia de Bombay (India), el obispo de Natchez (Mississippi, USA) y los obispos de Borussia (Alemania), ibíd., p. 175. Otros 15 episcopados, ibíd., p. 178.

${ }^{68}$ Lo solicitaban 28 episcopados, entre los que se encontraban los padres de la provincia de Venezuela, el arzobispo de Guatemala y los obispos de las provincias de Bélgica y de Tokio (Japón), ibíd., p. 163; el obispo de San Alberto (Canadá), ibíd., p. 168; el arzobispo de Kingston (Canadá); el obispo de Clermont (Francia), ibíd., p. 168; los padres de la provincia de Quito (Ecuador), ibíd., p. 170; y otros nueve episcopados, entre los cuales los obispos de Brasil, los de la provincia de Michoacán (México) y los obispos de Irlanda, ibíd., p. 175;

${ }^{69}$ Diez episcopados entre los cuales los padres de la provincia de Burgos (España), de Montreal (Canadá) y de Escocia, ibíd., p. 174; los padres de las provincias de Poznan (Polonia) 
dispensar en tercer y cuarto grado ${ }^{70}$, o que simplemente fuese un impedimento impediente.

El código conservó el impedimento de consanguinidad en los mismos términos en los que se refería a la línea recta, pero lo redujo al tercer grado -contado a la manera canónica- en la línea colateral (can. 1076), acogiéndose, así, en parte, la sugerencia del arzobispo peruano. Por lo demás, el impedimento de consanguinidad en tercer grado de la línea colateral era de grado menor (can. $1042 \$ 2 \mathrm{n}^{\circ}$ 1), por lo que se dispensaba fácilmente, aunque adoleciese de vicio de obrepción o subrepción (can. 1054). En segundo grado de línea colateral, es decir entre primos hermanos, se dispensaba con facilidad y no estaba reservado a la Santa Sede, como sí lo estaba el impedimento de consanguinidad en segundo grado mezclado con primero, esto es, tíos con sobrinos, para cuya dispensa, además, se requerían causas más graves. La dispensa de los demás grados quedaba reservada a la Santa Sede. El código de 1983 dio un paso más al reducir el impedimento hasta el cuarto grado en la línea colateral (can. $1091 \$ 2$ ) pero ahora contado según el modo romano (can. 108), por lo que recién en ese año se terminó de acoger por completo la sugerencia del arzobispo peruano; además, en lo referido a la dispensa del impedimento existente entre tíos(as) y sobrinas(os), no lo dejó reservado a la Santa Sede (can. $1078 \$ 2)$.

En cuanto a la afinidad, también ella fue conservada en el código de 1917, si bien la disciplina antecodicial fue profundamente reformada, porque, a partir del código, la afinidad sólo tuvo su origen en el matrimonio válido, estuviese o no consumado y dirimía el matrimonio en cualquier grado de la línea recta y hasta el segundo grado en la línea colateral (can. $1077 \$ 1$ ). Se acogía, pues, la petición general del informe del arzobispo Tovar y la de los otros episcopados que habían solicitado la reducción del impedimento al segundo grado de la línea colateral. El código canónico de 1983 también dio un paso más en esta materia, al eliminar el impedimento de afinidad en la línea colateral, dejándolo sólo reducido a la línea recta (can. 1092).

b) Extensión a la Iglesia universal de la facultad de celebrar tres misas el día de la conmemoración de los fieles difuntos. En los primeros años de la Iglesia, viviendo todavía los apóstoles, ellos celebraban la Misa cuando y donde podían. Al aumentar el número de obispos y sacerdotes, se introdujo la práctica de celebrar una Misa en fechas determinadas, presidida por el obispo o un presbítero representante suyo, y concelebrada con los demás sacerdotes. Desde el siglo IV se iniciaron las misas privadas, quedando los sacerdotes en libertad para decirlas por su cuenta, incluso varias veces al día si lo juzgaban conveniente. Inocencio III (1198-1216), a efectos de evitar graves abusos introducidos, "con motivo de las sórdidas exacciones de limosnas"71, prohibió a los sacerdotes celebrar más de una Misa al día, exceptuada la festividad del Nacimiento del Señor ${ }^{72}$.

y de Ruan (Francia), ibíd., p. 176; el obispo de Nueva York (USA), los padres de la provincia de Cincinnati (USA) y el obispo de Albano (Italia), ibíd., p. 177;

${ }^{70}$ Los obispos de Apulia (Italia), ibíd., p. 177.

${ }^{71}$ Donoso, Justo, cit. (n. 49), II, p. 68.

${ }^{72}$ Alonso Lobo, OP., Arturo - Mígueles Domínguez, Lorenzo - Alonso Morán, OP., 
Por antigua costumbre que, según se creía, emanaba de privilegio apostólico, en las provincias españolas de Aragón, Valencia, Cataluña e isla de Mallorca, todos los sacerdotes seculares celebraban el día de conmemoración de los fieles difuntos dos Misas y los regulares tres, todas ellas con estipendio. Benedicto XIV (17401758), a instancia de Fernando VI (1746-1759), mediante la constitución Quod expensis, de 26 de agosto de $1748^{73}$, extendió a todos los sacerdotes seculares y regulares, residentes en cualquier punto de los dominios de España, el privilegio de que pudiesen celebrar tres Misas en el día expresado, con la expresa condición de que los nuevamente privilegiados, estuviesen obligados a aplicar las dos Misas del indulto, en general, por todos los fieles difuntos, no pudiendo recibir estipendios por ellas, bajo pena de suspensión reservada a su Santidad. Pero nada innovó en cuanto a los que ya gozaban del privilegio en las provincias mencionadas, los cuales pudieron recibir estipendios por cada una de las dos o tres Misas que celebrasen en virtud del privilegio. El pontífice otorgó la misma gracia al reino de Portugal, a ruegos de Juan V (1706-1750) ${ }^{74}$. León XIII (1878-1903), mediante las letras apostólicas Trans oceanum, de 18 abril $1897^{75}$, lo amplió a "todas y cada una de las circunscripciones de América Latina, sin excepción” (n. VII).

La propuesta del arzobispo de Lima fue recogida por Klumper ${ }^{76}$ en el resumen general de los postulata episcoporum que elaboró una vez que llegaron las respuestas episcopales a Roma. No fue el único en hacer esta sugerencia porque en el mismo sentido se pronunciaron los padres de la provincia de Lvov (Ucrania). Otros, como el obispo norteamericano de San Antonio ${ }^{77}$ pedía que se concediere a todos los sacerdotes el privilegio de binar con ocasión de la conmemoración de todos los fieles difuntos. Con todo, cuando en 1913 se envió a los obispos del mundo el proyecto del Libro III del Código de Derecho Canónico para que formularan sus observaciones, el canon 84 del mismo en su parágrafo primero ${ }^{78}$ no recogía la iniciativa del arzobispo limense, pues se permitía celebrar tres Misas sólo el día del nacimiento del Señor. Algo después, sin embargo, Benedicto XV (1914-1922), para ayudar espiritualmente al gran número de víctimas de la primera Guerra Mundial, extendió dicha gracia a todo el orbe, mediante la constitución Incruentum

Sabino, Comentarios al Código de Derecho Canónico (Madrid, Bac, 1963); II, p. 204.

${ }^{73}$ Su texto en Fontes, III, pp. n. 2391.

${ }^{74}$ Alonso Lobo, OP., Arturo - Mígueles Domínguez, Lorenzo - Alonso Morá, OP., Sabino, cit. (n. 72), p. 205; Donoso, Justo, cit. (n. 49), II, p. 69.

${ }^{75}$ Fontes, III, pp. 512-515, n. 633. Su texto bilingüe, en Retamal Fuentes, Fernando, cit. (n. 50), II, 2, pp. 808-817.

${ }^{76}$ Postulata, cit. (n. 14), p. 110.

${ }^{77}$ Ibíd.

78 "Proyecto de Libro III", can. 84: “\$1. Con excepción del día del Nacimiento del Señor en el que se puede ofrecer tres veces el sacrificio eucarístico en la Iglesia latina, no es lícito a los sacerdotes celebrar varias Misas en un día si no es en virtud de indulto apostólico o de autorización concedida por el Ordinario. $\$ 2$. No puede, sin embargo, conceder el Ordinario esta facultad a no ser cuando una parte notable de fieles no puede oír Misa en día festivo de precepto a causa de la escasez de sacerdotes; más no está dentro de sus atribuciones el permitir que un mismo sacerdote celebre más de dos Misas". 
altaris, de 10 de agosto de $1915^{79}$, imponiendo la obligación de celebrar la segunda por los difuntos en general y la tercera por las intenciones del Papa, ambas sin estipendio. Esto ocurría cuando el Código todavía no se promulgaba, por lo que pudo modificarse el proyecto de Libro III y recoger esta innovación pontificia en el que sería el canon 806 del código promulgado, cuyo tenor es casi igual al del proyecto, con la innovación de incluir también el día de todos los difuntos ${ }^{80}$.

c) Atenuación de la disciplina del ayuno y abstinencia de un modo uniforme para toda la Iglesia, sin perjuicio de los privilegios particulares concedidos por la Santa Sede. "Todos los católicos reconocen la grave obligación de observar los ayunos prescritos por la Iglesia... Los ayunos de obligación, según la actual disciplina de la Iglesia, son, el de Cuaresma, el de las cuatro Témporas, y el de las Vigilias. El más antiguo y solemne ayuno es el de la Cuaresma. Introducido y observado constantemente desde el origen de la Iglesia, si bien no se puede decir que haya emanado de un expreso precepto divino, consta de la tradición y del común sentir de los escritores eclesiásticos, que fue instituido por los Apóstoles a imitación de los ayunos de Moisés y Elías y del de Jesucristo en el desierto" ${ }^{81}$. Por lo que se refiere a la abstinencia de carnes, "obliga por ley eclesiástica general en todos los ayunos de la Iglesia, y además todos los domingos de cuaresma y los viernes y sábados de todo el año", si bien respecto de los sábados fuera de la cuaresma, Benedicto XIV la había dispensado respecto de las provincias de España e Indias, por la constitución Jampridem, de 23 de enero de $1745^{82}$. Aparte de esta dispensa privativa para España e Indias, los mismos territorios estaban beneficiados por los privilegios de la bula de cruzada, otorgados por la Silla Apostólica a favor de los habitantes de las provincias sujetas al dominio del rey de España ${ }^{83}$.

Durante el Concilio Vaticano I los obispos de Francia habían solicitado que se uniformasen las leyes del ayuno y abstinencia y que se viera si convenía mitigarlas, propuesta que había sido conocida por el arzobispo limense porque se incluía en el artículo que por esas semanas publicaba El amigo del clero $^{84}$; de hecho, la formulación de la sugerencia limense estaba redactada en términos similares a la de los obispos galos. Un avance en este sentido fue la constitución

\footnotetext{
${ }^{79} A A S .16$ (1924), p. 116. Fue publicada en EAC., 24 (1 noviembre 1915), 862, pp. 461-464.

${ }^{80}$ CIC 1917, canon 806: "\$ 1. Excepción hecha de los días de la Natividad del Señor y de la Conmemoración de todos los fieles difuntos, en los cuales se puede ofrecer tres veces el Sacrificio Eucarístico, no es lícito al sacerdote celebrar varias Misas en un día si no es en virtud de indulto apostólico o de autorización concedida por el Ordinario local. $\$ 2$. No puede, sin embargo, conceder el Ordinario esta facultad a no ser cuando, según su prudente juicio, una parte notable de fieles no puede oír Misa en día festivo de precepto a causa de la escasez de sacerdotes; más no está dentro de sus atribuciones el permitir que un mismo sacerdote celebre más de dos Misas".

AAS. 16 (1924), p. 116.

${ }^{81}$ Donoso, Justo, cit. (n. 49), II, p. 223.

${ }^{82}$ Ibíd, p. 225.

${ }^{83}$ Benito Rodríguez, José Antonio, La bula de cruzada en Indias (Madrid, Fundación Universitaria Española, 2002); Donoso, Justo, cit. (n, 49), II, pp. 226-227.

${ }^{84}$ Véase antes n. 53.
} 
Trans aceanum de León XIII ${ }^{85}$ que había establecido que "los indios y los negros no están obligados a ayunar sino en los viernes de Cuaresma, en el Sábado Santo y en la vigilia de la Navidad de Nuestro Señor Jesucristo" (n. XII), y "además los indios y los negros, sin obligación de erogar ningún tipo de limosna, pueden usar del indulto llamado 'cuaresmal', que la Sede Apostólica otorga a los fieles de la respectiva diócesis o región; por consiguiente pueden alimentarse con carnes, huevos y lacticinios en todos aquellos dias en que lo prohibe la Iglesia, con excepción -en lo que se refiere a las carnes- de los días señalados arriba, en el n. XII' (n. XIII). Poco después, el 6 de julio de 1899 los arzobispos y obispos de América Latina, reunidos en Roma en Concilio plenario, obtuvieron de la Santa Sede, por diez años, dispensa de la ley del ayuno y abstinencia para los fieles que la pidiesen, inclusos los religiosos de ambos sexos, quedando sólo obligados al ayuno sin abstinencia de carnes los viernes de Adviento y miércoles de Cuaresma; al ayuno con abstinencia, el miércoles de Cenizas, los viernes de Cuaresma y el Jueves Santo; y a la abstinencia de carnes sin ayuno en las vigilias de Navidad, Pentecostés, Asunción y San Pedro y San Pablo. Además, en los días de ayuno, todos, incluidos los regulares, aun cuando no pidiesen una especial dispensa, podían siempre emplear huevos y lacticinios en la comida de la noche ${ }^{86}$.

La propuesta del arzobispo de Lima tocaba un tema sensible pues no fueron pocas las sugerencias que se recibieron en $\operatorname{Roma}^{87}$, si bien en los términos propuestos por el arzobispo Tovar sólo hubo otra propuesta ${ }^{88}$; y de todas ellas sólo otro episcopado de América Latina, el chileno, hizo sugerencias en materia de ayuno y abstinencia ${ }^{89}$. Parece claro que así fuese, pues los habitantes de América Latina, desde antiguo, tenían privilegios de los que se carecía, al menos en forma generalizada, en otras partes. Se inspiraba el arzobispo en la experiencia latinoamericana que establecía un régimen privilegiado aplicable en una región extensa, por lo que era posible aplicarlo de manera general.

El Código de Derecho Canónico actuó como lo sugería el arzobispo, estableciendo una disciplina menos rigurosa para la generalidad de la Iglesia ${ }^{90}$.

${ }^{85}$ Véase antes n. 50.

${ }^{86} \mathrm{Su}$ texto bilingüe en Retamal Fuentes, Fernando, cit. (n. 50),. II, 2, pp. 880-883.

${ }^{87}$ Klumper recoge 45 propuestas. Cf. Postulata, cit. (n. 14), pp. 199-205.

${ }^{88}$ De los obispos Irentonensis, ibíd., p. 201.

${ }^{89}$ Sugerían, en cuanto al ayuno y abstinencia en los días feriados: i) determinar las clases de alimentos que puedan tomarse en poca cantidad en la mañana y en la cena vespertina, y la cantidad de estos; ii) eximir de no promiscuar a todos aquellos que por alguna causa natural o por dispensa, o por privilegio, no están obligados a la abstinencia del uso de la carne; iii) eximir también de la abstinencia y de no promiscuar a los huéspedes y otras personas que todos los días comen en la casa cuyos dueños o familia están exentos o libres de las antedichas obligaciones. Postulata, cit. (n. 14), p. 205. Salinas Araneda, Carlos, El primer aporte de los obispos chilenos a la codificación del Derecho canónico de 1917: los "postulata episcoporum", en Revista de Estudios Histórico-Jurídicos, 30 (2008), pp. 317-342, esp. 334.

${ }^{90}$ Así, la ley de la abstinencia "prohíbe comer carne y caldo de carne, pero no prohíbe comer huevos, lacticinios y cualesquiera condimentos, aunque sean de grasa de animales" (can. 1250); en tanto que la ley del ayuno "prescribe que no se haga sino una sola comida al día; pero no prohíbe tomar algún alimento por la mañana o por la tarde, con tal que se observe, respecto de la cantidad y la calidad, la costumbre aprobada en cada lugar"; tampoco se prohibía mezclar carne 
d) Autorización, en todo el año, de la misa nupcial, como está concedido a los indios en las letras apostólicas 'Trans oceanum', a fin de evitar que los fieles que se casan en el tiempo vedado se queden sin recibir la bendición nupcial 'infra Missam'. "Entre las condiciones prescritas por el Derecho para la celebración del matrimonio, cuéntanse también las bendiciones nupciales. Dos son estas bendiciones. La primera tiene lugar en el acto mismo de la celebración, inmediatamente después de la expresión del consentimiento... La segunda bendición es la que se confiere en la misa nupcial, después de la oración Libera nos, y ésta es la bendición que se llama bendición solemne; cuya institución es antiquísima en la Iglesia. Esta bendición solemne (velación se llama en América) es de precepto respecto de las primeras nupcias" ${ }^{91}$. Esta segunda bendición, sin embargo, no podía impartirse en todo tiempo, pues, según el concilio de Trento $^{92}$, había períodos litúrgicos en que ella estaba prohibida, en concreto, desde la primera dominica de Adviento hasta Epifanía, y desde el miércoles de Ceniza hasta la octava de Pascua inclusive. En los demás tiempos, el mismo concilio permitía que los matrimonios se celebraren solemnemente, con la advertencia de "que cuidarán los Obispos se celebren con la modestia y honestidad debida".

Había teólogos que pretendían que en los tiempos señalados no sólo estaban prohibidas las bendiciones solemnes, sino la celebración misma de los matrimonios ante el párroco y los testigos, lo que era contradicho por otros teólogos que alegaban en su favor "la terminante autoridad del Ritual Romano" según el cual el matrimonio podía celebrarse en todo tiempo. "La general práctica en todas las iglesias de la América Española, está de acuerdo con esta declaración del Ritual; y por consiguiente, se omite, en los tiempos prohibidos, la solemne bendición nupcial, pero jamás la celebración del matrimonio" 93 . El problema era que quienes contraían matrimonio en los tiempos prohibidos no recibían la bendición solemne y así continuaban permanentemente, lo que era motivo de preocupación, especialmente porque esto sucedía con frecuencia entre los indígenas. Esta preocupación se veía con frecuencia en el período indiano, donde algunos sínodos de la época se preocupaban particularmente del tema ${ }^{94}$.

y pescado en la misma comida, ni cambiar la colación de la noche con la comida del mediodía (can. 1251). En cuanto a los días, la ley de la sola abstinencia se debía observar todos los viernes del año (can. $1252 \$ 1$ ), en tanto que la abstinencia y el ayuno obligaban el miércoles de Ceniza, los viernes y sábados de Cuaresma y los tres días de las cuatro Témporas, las vigilias de Pentecostés, de la Asunción de la Madre de Dios, de la fiesta de Todos los Santos y de la Natividad del Señor (can. $1252 \$ 2$ ). La ley de solo el ayuno se debía observar todos los restantes días de la Cuaresma (can. $1252 \$ 3$ ). Cesaba la ley de la abstinencia, o de la abstinencia y del ayuno, o del ayuno solo, en los domingos o fiestas de precepto, exceptuadas las fiestas que caían en Cuaresma, y no se anticipaban las vigilias; cesaba también dicha ley el Sábado Santo después de mediodía (can. $1252 \$ 4)$. Estaban obligados a guardar la abstinencia cuantos hubieren cumplido los siete años de edad (can. 1254\$1) y el ayuno todos, desde los 21 años de edad cumplidos hasta que hubieren comenzado el sexagésimo (can. $1254 \$ 2$ ).

${ }^{91}$ Donoso, Justo, cit. (n. 49), II, p. 180.

${ }^{92}$ Conc. Trid. ses. XXIV, cap. 10 de ref. matr.

${ }^{93}$ Donoso, Justo, cit. (n 49), II, p. 172.

${ }^{94}$ El sínodo de Lima de 1613 se expresaba en estos términos: "porque la experiencia muestra que algunos después de desposados suelen cohabitar mucho tiempo y hacer vida maridable 
En la undécima de las normas contenidas en las letras apostólicas Trans oceanum de León XIII" ${ }^{95}$, se disponía que "los indios y los negros pueden recibir la bendición nupcial en cualquier época del año, con tal de que no echen mano de aparatosa pompa en aquellos tiempos litúrgicos en que dichas bendiciones son probibidas por la Iglesia". Se trataba, empero, de un privilegio, porque la bendición solemne seguía prohibida en algunos tiempos del año para quienes no eran indios ni negros de América Latina. De hecho, el Concilio plenario de América Latina, abordando expresamente esta materia, reiteraba una declaración hecha por el Santo Oficio el 31 de agosto de 1881, en la que se reiteraba la disciplina tradicional sobre esta materia $^{96}$. Es por lo que el arzobispo de Lima pedía su extensión a toda la Iglesia.

Los obispos peruanos no fueron los únicos en preocuparse de este tema. $\mathrm{Su}$ propuesta fue recogida por Klumper conjuntamente con la de los padres de la provincia de Albi (Francia). En términos similares se plantearon los padres de la provincia de Lvov (Ucrania), en tanto que otros postulaban que se restringiera el tiempo vedado a unos pocos días ${ }^{97}$, o que se permitieran las bendiciones en el tiempo de Adviento ${ }^{98}$, o en otros momentos de los prohibidos ${ }^{99}$.

El proyecto del Libro III del código que se preparaba, enviado oportunamente a los obispos para sus observaciones, conservaba la disciplina antigua, si bien reducía un poco el tiempo en que la bendición nupcial solemne estaba prohibida. En efecto, el canon 385 del proyecto, después de afirmar que el matrimonio podía celebrarse en cualquier tiempo $(\$ 1)$, disponía que la bendición solemne no podía darse desde el primer domingo de Adviento hasta el día de Navidad inclusive, y desde el miércoles de Ceniza hasta el domingo de Pascua inclusive ( $\$ 2)$, no obstante los cual los ordinarios del lugar podían permitir la bendición solemne en dichas fechas con causa justa advirtiendo a los esposos de abstenerse de pompa

sin haberse velado, contra lo que ordena el Santo Concilio Tridentino; mandamos que los curas procuren que sus feligreses no cohabiten en manera alguna hasta que se hayan hecho las velaciones y hayan recibido las bendiciones de la Iglesia; y si acaso se hubieren pasado seis meses desde el día del desposorio sin que se haya velado, darán noticia de ello a nuestro provisor y a los vicarios para que los excomulguen y penen como les pareciere, hasta que cumplan con su obligación; y cuando los que se han de casar fueren pobres o indios o negros, en que hay mayor peligro de que se difieran sus velaciones, harán que se desposen y velen en un día, como sea tiempo, en que puedan velarse”. Libro IV, tít. I, cap. X. Véase también el sínodo de Concepción (Chile) de 1744, cap. 5, const. 12 .

${ }^{95}$ Véase antes nota 50.

${ }^{96}$ Concilio plenario para América Latina, decreto 598.

${ }^{97} \mathrm{El}$ arzobispo de Acheron et Matheran (India inglesa); los padres de la provincia de Naxos (Grecia); el arzobispo de Tolosa (Francia); los padres de la provincia de Besançon (Francia). Postulata, cit. (n. 14), p. 189.

${ }^{98}$ Los padres de la provincial de Burgos (España), ibíd.

99 "Nuptiarum solemnitas permittatur a feria quarta post Pascha (et statim post octavam Nativitatis)", padres de la provincia de Reims (Francia); obispo de Tulle (Francia). "Tempos feriatum sint Vigiliae, Quatuor Tempora et duae hebdomades ante festum Paschatis", obispo de Montauban (Francia). "Tempus feriatum non protrahatur ultra festum Paschatis et ultra festum Nativitatis D. N.”, padres de la provincia Sens (Francia); provincia de Cincinati (USA); obispo de Borussiae (Alemania), padres de la provincia de Boston (USA). Ibíd. 
excesiva $(\$ 3)$. Fue la disciplina que finalmente se recogió en el Código de Derecho Canónico ${ }^{100}$, por lo que la petición de los obispos peruanos no fue acogida.

e) Delegación permanente a los obispos para enajenar los bienes eclesiásticos, previas las condiciones exigidas por Derecho. La legislación canónica acerca de la enajenación se ha ido formando progresivamente con una triple finalidad: i) reivindicar por parte de la Iglesia el Derecho de enajenar sus bienes, siempre que ella lo estime oportuno; ii) proteger su patrimonio de malversaciones y dilapidaciones; iii) establecer las leyes y normas para regular estas materias, en cuya configuración es posible distinguir cuatro períodos ${ }^{101}$. El primero de ellos abarca aproximadamente hasta el siglo IV, caracterizado por la atribución de grandes facultades en esta materia al obispo diocesano y la progresiva tendencia a restringir la facultad de enajenar los bienes de la Iglesia, normas motivadas por los abusos cometidos en detrimento de los intereses de la Iglesia. El segundo período va del siglo IV al XV, en concreto, la constitución Ambitiosae de Paulo II (14581471) de $1468^{102}$, caracterizándose por la afirmación de la inalienabilidad de los bienes eclesiásticos y el establecimiento de diversos controles superiores necesarios para que los obispos y los clérigos pudiesen enajenar los bienes eclesiásticos, como la aprobación del concilio provincial o de los obispos vecinos y la especial autorización del Romano Pontífice establecida por Paulo II en la constitución Ambitiosae. Las penas establecidas para quienes incumplieran estas exigencias eran la nulidad de los actos realizados; la excomunión al que enajenaba y al que recibía los bienes enajenados; y al que enajenaba bienes eclesiásticos "inconsulto Romano Pontifice" se le castigaba con el entredicho ingressus Ecclesiae, si gozaba de la dignidad pontifical o abacial, quedando eo ipso suspensus del régimen y de la administración de su iglesia o monasterio si durante los seis meses siguientes no cambiaba de actitud; si el enajenante era un eclesiástico de condición inferior, se le privaba del oficio. El tercer período abarca desde el siglo XVI hasta el Código de Derecho Canónico de 1917, en el que se siguen básicamente las líneas establecidas en la constitución Ambitiosae de Paulo II, retomadas por Urbano VIII (1623-1644) ${ }^{103}$ y actualizadas por el beato Pío IX (1846-1878) ${ }^{104}$ quien mantuvo la excomunión latae sententiae para los que intentaban enajenar o adquirir bienes de la Iglesia sin el beneplácito de

${ }^{100}$ Código de Derecho Canónico, can. 1108: $\$ 1$. Puede contraerse matrimonio en cualquier tiempo del año. $\$ 2$. Solamente está prohibida la bendición solemne de las nupcias desde la primera dominica de Adviento hasta el día de la Natividad del Señor inclusive y desde el miércoles de Ceniza hasta el domingo de Pascua también inclusive. $\$ 3$. Pero pueden los Ordinarios locales, observando las leyes litúrgicas, permitir por alguna causa justa que se dé la bendición aun en los tiempos expresados, amonestando a los esposos para que se abstengan de pompa excesiva”.

${ }^{101}$ Aznar GiL, Federico R., La administración de los bienes temporales de la Iglesia ${ }^{2}$ (Salamanca, Publicaciones Universidad Pontificia de Salamanca, Biblioteca Salmanticensis Estudios 67, 1993), pp. 401-403.

${ }^{102}$ Extravag. Com. 3,4,1.

${ }^{103}$ Fontes, V, pp. 230-231.

${ }^{104}$ Constitución Apostolicae Sedis, de 1869, en ASS., 5 (1869), p. 299; Fontes, III, pp. 24-31. 
la Sede Apostólica. El cuarto período se inicia en 1917 con el Codex Iuris Canonici, que acogió sustancialmente la disciplina anterior.

Enseñaba Donoso ${ }^{105}$, a quien hemos de situar en el tercer período, que el concepto de enajenación en Derecho canónico era un concepto amplio, pues no sólo comprendía todo acto por el cual se transfería a otro el dominio de una cosa, como la donación, venta o permuta, sino también la enfiteusis, el feudo, la locación de más de tres años, el empeño, la hipoteca y, en fin, toda transacción en la que había traslación de dominio. Junto a este concepto amplio de enajenación, el Derecho se encargaba de señalar los bienes cuya enajenación estaba prohibida: i) los bienes inmuebles o raíces, bajo los cuales quedaban comprendidos los Derechos, acciones, servidumbres, censos o réditos anuales; ii) los muebles preciosos, entendiéndose por estos los vasos de oro y plata, las piedras preciosas, los ornamentos ricos, las reliquias insignes de santos, una biblioteca copiosa; iii) los ganados de ovejas, vacas u otras especies, pero no sus frutos o partos que podían enajenarse; iv) los árboles frutales o necesarios a un predio que, al cortarse, se deteriore notablemente ${ }^{106}$.

Que hubiera prohibición de enajenar los bienes eclesiásticos no significaba que su enajenación no fuera posible; se requería, sin embargo, que se cumplieran las exigencias que el mismo Derecho se encargaba de fijar: por de pronto, debía haber causa justa, entendiéndose por tal: i) evidente necesidad de la Iglesia, a que no se podía subvenir de otro modo, como podía ser reparar la iglesia que amenaza ruina; ii) manifiesta utilidad de la iglesia; iii) piedad para socorrer a los necesitados; iv) agregando algunos canonistas el caso de incomodidad o escasa utilidad, cuando la posesión de la cosa, p. ej., fuese notablemente molesta o dispendiosa. Cualquiera de estas causas era suficiente para la enajenación de un bien eclesiástico. Pero, además, era menester el cumplimiento de algunas solemnidades: i) debía preceder el conocimiento y deliberación del capítulo o convento, que debía deliberar acerca de la existencia de justa causa de enajenación y conveniencia; ii) el consentimiento de todo el capítulo o convento o, al menos, de la mayor parte del mismo si la enajenación la hacía el obispo; o el consentimiento del obispo, si la enajenación la hacía alguna autoridad inferior a él sometida, como un párroco; iii) el consentimiento y venia del Sumo Pontífice, exigencia que en América, por la distancia y difícil recurso a la Santa Sede no se requería en la época en que Donoso publicó sus Instituciones, costumbre que con la constitución Apostolicae Sedis, de Pío IX quedó sin efecto, pues ésta abrogó las costumbres contrarias en que se fundaban algunos canonistas para sostener que la extravagante Ambitiosae de Paulo II, que prescribía este requisito, no estaba vigente en algunos lugares, entre ellos, América Latina.

${ }^{105}$ Donoso, Justo, cit. (n. 49), II, pp. 278-281.

${ }^{106}$ De estas prohibiciones había excepciones, en concreto, ciertas donaciones que se permitía hacer a quienes tenían la plena administración de las cosas temporales: i) ciertas pequeñas donaciones que eran conformes por costumbre; ii) las que demandaba la piedad y misericordia, porque se entendía que los bienes eclesiásticos estaban gravados con esa carga; iii) las donaciones remuneratorias, hechas con título de justa gratitud por méritos especiales contraídos a favor de la Iglesia. 
El no cumplimiento de estas exigencias traía aparejados varios efectos: i) por de pronto, la nulidad de la enajenación que ipso facto era nula; ii) la excomunión mayor en que incurrían todos los que enajenaban y suscribían la enajenación como aquellos en cuyo favor se hacía; iii) la prohibición del ingreso en la iglesia impuesta a los obispos y abades, los cuales, siendo contumaces por seis meses, quedaban suspendidos del beneficio o dignidad; si el enajenante era un eclesiástico de inferior condición, se la privaba del oficio.

A la luz de la disciplina que acabo de resumir y que era la vigente al momento de la propuesta de los obispos peruanos, resulta claro el tenor de la sugerencia limense: deseaban continuar con el régimen que durante largo tiempo había imperado en América, obviando la exigencia de acudir a la Sede Apostólica para obtener su autorización para le enajenación de bienes eclesiástico, lo que, al no poder hacer ahora por costumbre contraria como había ocurrido durante años por haber quedado derogada por la constitución Apostolicae Sedis de Pío IX, pretendían obtener por una delegación permanente. La propuesta de los obispos de Perú fue recogida por Klumper ${ }^{107}$ conjuntamente con la de los obispos de la provincia de Cincinnati, los que agregaban un dato que no aparecía en la proposición limeña: que de la enajenación debía darse cuenta a la Santa Sede en la visita ad limina.

El proyecto de Libro III del código, De rebus ${ }^{108}$, no eliminó la exigencia de la aprobación por parte de la Santa Sede, por lo que no acogía la propuesta limense; pero el canon 812 estableció una limitación cuantitativa al disponer que era la Santa Sede la legítima autoridad que debía autorizar la enajenación sólo respecto de aquellos bienes que excedían los 25.000 liras o francos. Fue la misma disciplina que, con variantes en la redacción y en las cantidades, pasó al Codex en el canon $1532^{109}$.

${ }^{107}$ Postulata, cit. (n. 14), p. 235.

108 “Proyecto de Libro III”, can. 810: “\$ 1. Quedando a salvo lo que ordena el canon 558, para enajenar bienes eclesiásticos inmuebles o muebles que se pueden conservar, se requiere: $1^{\circ}$ Tasación de la cosa hecha por peritos honrados; $2^{\circ}$ Causa justa, es decir necesidad o utilidad de la Iglesia o piedad; $3^{\circ}$ Licencia del Superior legítimo, sin la cual la enajenación será inválida. $\$ 2$. Tampoco se omitirán otras diligencias oportunas que dicho Superior habrá de prescribir, según las diversas circunstancias, para evitar daños a la Iglesia”. Can. 812: "\$1. Tratándose de objetos cuyo precio exceda las 25.000 liras o francos, o de objetos preciosos, el superior legítimo de que trata el canon $810 \$ 1 \mathrm{n}^{\circ} 3$, es la Sede Apostólica. $\$ 2$. Tratándose de objetos cuyo pecio no excede las 1000 liras o francos, es el Ordinario del lugar, oído el consejo de administración y con el consentimiento de aquellos a quienes interese. $\$ 3$. Tratándose de objetos cuyo precio oscila entre las 1000 y 25.000 liras o francos, es el Ordinario del lugar, con tal que obtenga el consentimiento así del cabildo catedral como del consejo de administración, y también de aquellos a quienes interese".

${ }^{109}$ Código de Derecho Canónico, can. 1530: "\$ 1 . Quedando a salvo lo que ordena el canon $1281 \$ 1$, para enajenar bienes eclesiásticos inmuebles o muebles que se pueden conservar, se requiere: $1^{\circ}$ Tasación de la cosa por peritos honrados hecha por escrito; $2^{\circ}$ Causa justa, es decir, necesidad urgente, o utilidad manifiesta de la Iglesia, o piedad; $3^{\circ}$ Licencia del Superior legítimo, sin la cual es inválida la enajenación. $\$ 2$. Tampoco se omitirán otras diligencias oportunas que dicho Superior habrá de prescribir, según las diversas circunstancias, para evitar daños a la Iglesia”. Can. 1532: "\$ 1. El Superior legítimo de que habla el canon 1530 $\$ 1$, número $3^{\circ}$ es la Sede Apostólica, si se trata: $1^{\circ}$ De bienes preciosos; $2^{\circ}$ De bienes cuyo valor exceda la cantidad de treinta mil liras o francos. $\$ 2$. Más tratándose de objetos cuyo 
f) Autorización a los obispos para que puedan permitir la celebración de la Misa en domicilio privado, por causas justas a su arbitrio. Los Hechos de los Apóstoles ${ }^{110}$ narran sobre la fracción del pan realizada en casas particulares, probablemente de cristianos acomodados para poder albergar, por ser más espaciosas, a los primeros cristianos que acudían en número cada vez mayor. Que ello ocurriera así era explicable, pues había relativamente pocos fieles y la Iglesia no tenía edificios en propiedad para esos fines. Una vez que pudo actuar con libertad inició la construcción de lugares apropiados para los actos cultuales, los que, con el correr de los siglos, se edificaron con profusión, con mayor o menor dimensión y suntuosidad según el número de fieles a quienes se destinaba o la devoción o titular que se iba a venerar ${ }^{111}$.

Durante los siglos de persecución es explicable que la Misa se celebrara en casas particulares e, incluso, en las habitaciones de los enfermos. Terminadas las persecuciones, y no obstante que ya no era necesario, se generalizó la práctica de celebrar la Eucaristía en casas particulares lo que llevó a abusos graves por lo que el Concilio de Trento debió ocuparse del tema, limitando mucho las facultades al respecto ${ }^{112}$. Es por lo que el arzobispo de Lima solicitaba autorización para poder permitir la celebración de la Misa en domicilio privado, por causas justas a su arbitrio. Su petición fue recogida por Klumper ${ }^{113}$ conjuntamente con la de los obispos de las regiones de Campania y de Aprutorium, ambas en Italia, quienes pedían lo mismo por razón de enfermedad o de otras causas graves a criterio de los obispos y por modo de acto.

Cuando ya se había iniciado el proceso codificador del Derecho canónico y el arzobispo de Lima había enviado a Roma hacía algunos años sus postulata, la S. Congregación de sacramentos, mediante el decreto In plenario, de 23 de diciembre de $1912^{114}$, dictó unas normas sobre la materia que me ocupa que sus-

valor no sobrepasa la cantidad de mil liras o francos, es Superior legítimo el Ordinario local, oído el Consejo de administración, a no ser que se trate de una cosa insignificante, y con el consentimiento de aquellos a quienes interese. $\$ 3$. Finalmente, si es cuestión de bienes cuyo precio oscila entre las mil y treinta mil liras o francos, lo es el Ordinario del lugar, con tal que obtenga el consentimiento así del Cabildo catedral como del Consejo de administración, y también de aquéllos a quienes interese. $\$ 4$. Cuando se trate de enajenar una cosa divisible, al pedir la licencia o el consentimiento para enajenarla deben expresarse las partes anteriormente enajenadas; de lo contrario es inválida la licencia".

${ }^{110}$ Act. 2,46: "Todos los días, con un solo corazón, frecuentaban asiduamente el Templo, partían el pan en las casas, tomaban juntos el alimento con alegría y sencillez de corazón". Act. 20,7-8: "El primer día de la semana nos reunimos para partir el pan. Pablo, que iba a partir al día siguiente, hablaba con ellos y prolongó el discurso hasta media noche. ${ }^{8} \mathrm{Había}$ muchas lámparas en el aposento alto en que estábamos reunidos".

${ }^{111}$ Alonso Lobo, OP. Arturo Mígueles Dominguez, Lorenzo - Alonso Morán, OP., Sabino, cit. (n. 72), II, pp. 226-227.

${ }^{112}$ Cons. Trid., sess. XXII, decr. sobre la Misa: "En segundo lugar, para evitar toda irreverencia, ordene cada Obispo en su diócesis [...] ni toleren que se celebre este santo Sacrificio por sacerdotes seculares o regulares, cualesquiera que sean, en casas particulares, y absolutamente fuera de la iglesia y de los oratorios dedicados exclusivamente al culto divino".

${ }^{113}$ Postulata, cit. (n. 14), p. 113.

${ }^{114}$ AAS., 4 (1912), p. 725. 
tancialmente pasaron al proyecto de Libro III y de allí al código. En efecto, en lo que me interesa, el canon 101 del proyecto ${ }^{115}$ disponía que los ordinarios locales podían otorgar licencia para celebrar fuera de una iglesia u oratorio, existiendo causa justa y razonable, en algún caso extraordinario y a manera de acto (\$3). En términos similares, con alguna precisión añadida, esta disciplina pasó al Código de Derecho Canónico que en el canon 822 reguló esta materia ${ }^{116}$; en lo que me interesa, disponía que "el Ordinario local... pueden, sólo con causa justa y razonable, en algún caso extraordinario y a manera de acto, conceder licencia para celebrar fuera de la iglesia u oratorio, sobre un ara consagrada y en lugar decoroso, pero nunca en el cuarto de dormir" $(\$ 4)$. La doctrina posterior ${ }^{117}$ precisaría los términos del canon explicando, por ejemplo, que esta gracia podía concederse sólo en casos extraordinarios, es decir, en circunstancias que no ocurren con frecuencia; con tal que exista justa causa, esto es, causa objetiva, y razonable, esto es, apreciada como tal por la autoridad, sin que fuera necesario que fuera grave; y debía ser por tiempo transitorio o en una necesidad pasajera, como enfermedades transitorias.

Como se puede apreciar, la petición del arzobispo de Lima fue acogida, pero sólo en parte, porque, si bien se concedió autorización a los ordinarios para que pudieren conceder licencia para celebrar la Misa fuera de las iglesias u oratorios, la concesión fue con limitaciones, no aceptándose la amplitud con que era postulada desde el Perú, en la que el límite era la causa justa a arbitrio del prelado.

g) simplificación del procedimiento vigente respecto de la solicitación en confesión, de manera que puedan los obispos una vez ciertos de la realidad del delito, imponer la pena correspondiente 'ex informata conscientia', a causa de las graves y casi insuperables dificultades que ofrece en la práctica observar los trámites

115 "Proyecto de Libro III”, can. 101: “\$ 1. La Misa debe celebrarse sobre ara consagrada y en iglesia u oratorio a norma de los cánones 438-481. \$2. El privilegio de celebrar dondequiera, en lugar honesto y decente y sobre piedra sagrada, esto es, el privilegio de altar portátil, es concedido por la Sede Apostólica. $\$ 3$. El Ordinario del lugar o, si se trata de una casa de religión exenta, el superior mayor pueden conceder celebrar fuera de iglesia u oratorio sólo con causa justa y razonable en algún caso extraordinario y a manera de acto transitorio. $\$ 4$. El privilegio de altar portátil no otorga facultad de celebrar en el mar".

${ }^{116}$ Código de Derecho Canónico, can. 822: "\$ 1 . La Misa debe celebrarse sobre ara consagrada y en iglesia u oratorio consagrado o bendecido a tenor del Derecho, salvo lo que se determina en el canon 1196. $\$ 2$. El privilegio de altar portátil se concede o por Derecho o por indulto solamente de la Sede Apostólica. $\$ 3$. Este privilegio ha de entenderse en el sentido de que lleva consigo la facultad de celebrar dondequiera, siempre que sea en lugar honesto y decoroso y sobre piedra sagrada, pero no en el mar. $\$ 4$. El Ordinario local o, si se trata de una casa de religión exenta, el Superior mayor pueden sólo con causa justa y razonable, en algún caso extraordinario y a manera de acto, conceder licencia para celebrar fuera de la iglesia u oratorio, sobre un ara consagrada y en lugar decoroso, pero nunca en el cuarto de dormir". Según el can. 1196: " $\$ 1$. Los oratorios domésticos no pueden ser consagrados ni bendecidos como las iglesias. $\$ 2$. Aun cuando los oratorios domésticos y los semipúblicos reciban la bendición común de lugares o casas o carezcan de toda bendición, deben, sin embargo, estar reservados para el culto divino exclusivamente y libres de cualesquiera usos domésticos”.

${ }^{117}$ Alonso Lobo, OP., Arturo - Míguelez Domínguez, Lorenzo - Alonso Morán, OP., Sabino, cit. (n. 72), pp. 229-230. 
de la legislación actual. La solicitación en confesión es un delito de antigua tipificación en la Iglesia. Al tiempo de la codificación se regulaba en la constitución Sacramentum poenitentiae de Benedicto XIV (1740-1758), de 1 de junio de $1741^{118}$. En ella, empero, no se regulaba la tramitación del proceso respectivo, el que era de competencia del Santo Oficio, el que juzgaba siguiendo el procedimiento que el mismo Santo Oficio tenía señalado. Es por lo que el ordinario local tenía que ceñirse a las normas dadas por este organismo vaticano, las que el arzobispo entendía que originaban "graves y casi insuperables dificultades" de ser observadas, por lo que pedía que pudiesen los obispos, una vez ciertos de la realidad del delito, imponer la pena correspondiente ex informata conscientia.

El código promulgado no innovó en esta materia ni tampoco acogió la sugerencia del arzobispo peruana, pues incluyó como apéndice al mismo la constitución Sacramentum poenitentiae de Benedicto XIV, reconociéndola como parte integrante del texto codicial, y la competencia de su conocimiento siguió en manos del tribunal del Santo Oficio que "procede según prácticas y estatutos peculiares y conserva sus propias costumbres; $y$ aun los tribunales inferiores, en las causas pertenecientes al tribunal del Santo Oficio, han de seguir las normas por el mismo dictadas" (can. $1555 \$ 1$ ). Estas causas se tramitaban en secreto, al que se puso término recién en $1965^{119}$.

\section{CONCLUSIONES}

Llegados al final de estas páginas en las que hemos presentado las propuestas hechas por el episcopado peruano a la codificación del Derecho canónico de 1917, en respuesta a la primera de las consultas hecha a ellos en 1904, podemos sintetizarlas en los siguientes puntos:

1. Nada más llegar la consulta a manos del arzobispo de Lima éste procedió a consultar a los obispos sufragáneos que se encontraban a la cabeza de sus respectivas diócesis, pues algunas de ellas estaban vacantes, siendo nombrados sus obispos residenciales cuando el plazo fijado por Roma había vencido -Chachapoyas, Huánuco, Huaraz-. Es por lo que la respuesta enviada a Roma sólo compromete, en principio, a los obispos que en esos momentos estaban en funciones, en concreto el arzobispo de Lima y los obispos de Arequipa, Cuzco, Guamanga o Ayacucho, y Puno.

2. Sólo en principio, pues la primera respuesta de los obispos consultados fue un simple acusar recibo de la consulta, ofreciendo una carta posterior en la que

\footnotetext{
${ }^{118}$ Se incluyó como documento V en el apéndice del Código de Derecho Canónico de 1917, que lo reconocía como parte integrante del mismo código. Su texto resumido en castellano en García Barberena, Tomás, Comentarios al Código de Derecho Canónico (Madrid, BAC, 1964), IV, pp. 607-609.

${ }^{119}$ Mediante el motu proprio Integrae servandae, de 6 diciembre 1965, publicado en $A A S$., 57 (1965), pp. 952-955, reforma confirmada por Pablo VI mediante la constitución apostólica Regimini Ecclesiae universae, de 15 agosto 1967, publicada en AAS., 59 (1967), pp. 885-928, que dieron al encartado facultad de defenderse e incluso elegir abogado entre aquellos que estén aprobados por la Congregación para la doctrina de la fe, sucesora del Santo oficio.
} 
abordarían el problema formulando las sugerencias que consideraren oportunas, sugerencias que no llegaron y que fueron la causa del retraso con que fue enviada la respuesta peruana a Roma, fuera del plazo fijado para ello por la Santa Sede.

3. Sólo el obispo de Puno, Ismael Puirredón, que a la sazón era, además, administrador apostólico de Trujillo, respondió algo más que los demás obispos, pero sólo se limitó a expresar la conveniencia de que hubiera un código procesal uniforme para todas las curias eclesiásticas.

4. No habiendo recibido ninguna comunicación posterior, el arzobispo procedió a reunir al consejo de administración arquidiocesana para escuchar sus opiniones y poder informar a Roma.

5. Como en la circular enviada desde Roma se ofrecía a los obispos la posibilidad de escoger uno de los consultores que ya habían sido nombrados por los cardenales y encargarle que los representara para someter a discusión y defender sus proposiciones en las reuniones de los consultores, fue designado como consultor de la provincia eclesiástica el padre Francisco Javier Wernz, de la Compañía de Jesús, que dos años después llegaría a ser prepósito general de la misma, uno de los canonistas más destacados del momento.

6. Ninguno de los obispos peruanos del momento tenía especial formación jurídica, como sucedía, por ejemplo, en Chile, donde algunos de los prelados habían estudiado Derecho en alguna de las dos universidades existentes a la sazón. La formación jurídica de los obispos del Perú se limitaba al Derecho canónico estudiado en el seminario, lo que tiene una directa incidencia en el número y en el contenido de las propuestas, contrastando en esto con las propuestas de otros episcopados, incluso latinoamericanos.

7. Dos de las propuestas del arzobispo de Lima tienen su inspiración directamente en proposiciones formuladas en el Concilio Vaticano I, algunas de las cuales fueron conocidas en Lima al tiempo que se preparaba la respuesta a Roma al ser publicadas en las páginas de El amigo del clero. Puede advertirse también cierta inspiración en las letras Trans oceanum del papa León XIII promulgadas pocos años antes.

8. Algunas de las propuestas limenses coinciden con las de otros episcopados, como la referida a la reducción de los impedimentos matrimoniales de consanguinidad y afinidad al segundo grado canónico o la bendición nupcial solemne en tiempos prohibidos. Se trataba de temas en los que la experiencia indicaba la necesidad de una reforma y en los que los obispos peruanos mostraron una especial sintonía con otros episcopados de la Iglesia.

9. Algunas propuestas de los obispos del Perú fueron acogidas parcialmente, como la de reducir el impedimento matrimonial de consanguinidad en línea colateral del cuarto al segundo grado, en circunstancias que el código finalmente aprobado lo redujo sólo hasta el tercer grado.

10. Alguna otra propuesta, sin embargo, fue acogida plenamente, como la reducir el impedimento matrimonial de afinidad del cuarto al segundo grado, contado según el modo canónico. Se trataba, empero, de una reforma necesaria, en la que coincidían con otros episcopados, por lo que su acogida no obedece a la sola 
insinuación de los obispos peruanos, sino a la necesidad de la misma manifestada por los obispos peruanos en consonancia con otros episcopados.

11. Alguna propuesta no tomada en consideración en un primer momento, terminó acogida en el código finalmente promulgado, pero ello ocurrió no por la sugerencia limense, sino por decisiones pontificias que, si bien coincidieron con la propuesta del arzobispo de Lima, estaban originadas en inquietudes diversas, como sucedió con la extensión al mundo entero de las posibilidad de celebrar tres Misas el día de los difuntos, que el papa dispuso para sufragio de los miles de muertos que estaba causando la primera Guerra Mundial. Mérito del arzobispo, quizá, fue haber llamado la atención sobre esa posibilidad.

12. Algunas propuestas están inspiradas en la constitución Trans oceanum de León XIII que otorgó privilegios especiales a los fieles de la iglesia latinoamericana. Como la de eliminar los impedimentos matrimoniales en 3 y 4 grado otorgada a los negros y a los indios, la de poder recibir la bendición nupcial solemne en cualquier tiempo del año, y también en lo referido al ayuno y abstinencia.

\author{
ANEXO \\ “POSTULATA"DE LOS OBISPOS DE LA PROVINCIA ECLESIÁSTICA DE LIMA \\ Carta del arzobispo de Lima, Manuel Tovar y Chamorro, a Pedro Gasparri, \\ secretario de la Comisión codificadora \\ Lima, 3 de octubre de 1904 \\ ASV. CIC ,1917, caja 96
}

Lima, octubre 3 de 1904/

Excmo. e Iltmo. Monseñor/ Pedro Gasparri, Secretario de la/ Comisión Cardenalicia encarga-/ da de la codificación del de-/ recho canónico

Excmo. e Iltmo. Monseñor/

Inmediatamente que re-/ cibí la respetable circular de S. E. Rma./ el Cardenal Secretario de Estado, enca-/ minada a obtener de cada una de las/ provincias eclesiásticas, su parecer respec-/ to de las alteraciones o cambios que pu-/ dieran introducirse en el Derecho canó-/ nico vigente, me dirigí a los Iltmos. y/ Rmos. S. S. Obispos sufragáneos y demás/ Ordinarios del Perú, para dar exacto/ cumplimiento al mandato de la San-/ ta Sede./

A causa de las distancias y/ por hallarse en visita pastoral algunos/ de los Prelados, retardaron sus respues-/ tas que se limitaron a acusar recibo/ de mi circular e indicar que oportu-/ namente manifestarían los puntos/ que, a su juicio, merecían ser modi-/ ficados en la legislación de la Iglesia.// Sólo el Iltmo. Sr. Puirredón,/ Obispo de Puno y Adminis-/ trador Apostólico de Trujillo expre-/ só la conveniencia de que hubiera/ un "Código procesal uniforme para/ todas las curias eclesiásticas"./

No habiendo recibido ninguna/ comunicación posterior de los Iltmos./ y Rmos. Ordinarios, procedí, por mi par-/ te, a reunir el Consejo de Administración diocesana para oír su ilustra-/ da opinión en esta importante materia.

De un modo unánime, expresaron/ los distinguidos sacerdotes que lo forman/ 
su parecer respecto de los puntos si-/ guientes: $1^{\circ}$ Adherirse a la petición/ antedicha del Iltmo. Sr. Obispo de/ Puno; $2^{\circ}$ Supresión de los impedi-/ mentos en $3^{\circ}$ y $4^{\circ}$ grados de consangui-/ nidad y afinidad para la validez/ del matrimonio; $3^{\circ}$ Extensión a la/ Iglesia universal de la facultad de/ celebrar tres misas el día de la Con-/ memoración de los fieles difuntos; $4^{\circ}$ Atenuación de la disciplina del/ ayuno y abstinencia de un modo/ uniforme para toda la Iglesia sin/ perjuicio de los privilegios particu-/ lares concedidos por la Santa Sede; $/ 5^{\circ}$ Autorización, en todo el año, de la/ misa nupcial, como está concedido// a los indios en las Letras

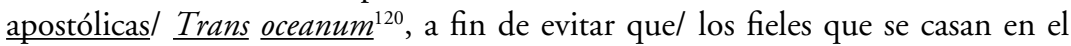
tiempo ve-/ dado se queden sin recibir la bendición/ nupcial infra Missam $^{121} ; 6^{\circ}$ Delegación/ permanente a los Obispos para enage-/ nar los bienes eclesiásticos, previas las/ condiciones exigidas por Derecho; $/ 7^{\circ} \mathrm{Au}-/$ torización a los mismos para que puedan/ permitir la celebración de la Misa en do-/ micilio privado por causas justas a su ar-/ bitrio; $8^{\circ}$ Simplificación del procedi-/ miento vigente respecto de la solicita-/ ción in confessione ${ }^{122}$, de manera que/ puedan los Obispos, una vez ciertos de/ la realidad del delito, imponer la pena/ correspondiente ex informata conscientia $^{123}$,/ a causa de las graves y casi insuperables/ dificultades que ofrece, en la práctica,/ observar los trámites de la legislación/ actual./

Estos son los puntos que la Comi-/ sión creyó que debían someterse respe-/ tuosamente a la deliberación de los Emi-/ nentísimos Cardenales, encargados por/ Su Santidad de preparar el proyecto de/ codificación del Derecho Canónico. Yo/ me adhiero a ellos, protestando desde/ ahora, mi absoluta y completa sumisión/ a cuanto disponga la Santa Sede, sin/ restricción alguna.//

Ruego a V. E. Iltma. que se/ digne escusar la demora de algunos/ días en la expedición de este informe/ por los motivos expuestos al princi-/ pio de este oficio./

Antes de terminarlo me es gra-/ to participar a V. E. Iltma. que, por/ el voto unánime de los SS. Obispos, / ha sido designado como consultor/ de esta provincia eclesiástica el R./ P. Francisco Javier Wernz./

Con los sentimientos de la más/ distinguida y respetuosa considera-/ ción, me suscribo de V. E. Iltma. afec-/ tísimo y obediente servidor/.

+Manuel, Arzobispo de Lima//.

[Recibido el 18 de enero y aprobado el 31 de julio de 2010].

\section{BiBLIOGRAFÍA}

Actas y decretos del Concilio Plenario de la América Latina celebrado en Roma el años del Señor de MDCCCCXCIX (1906, Ed. Facs., Librería Editrice Vaticana, Ciudad del Vaticano, 1999).

\footnotetext{
${ }^{120}$ Subrayado en el original.

${ }^{121}$ Subrayado en el original.

${ }^{122}$ Subrayado en el original.

${ }^{123}$ Subrayado en el original.
} 
Alonso Lobo, OP., Arturo - Migueles Domínguez, Lorenzo - Alonso Morán, OP., Sabino, Comentarios al Código de Derecho Canónico (Madrid, Bac, 1963), II.

AzNar GiL, Federico R., La administración de los bienes temporales de la Iglesia (Salamanca, Publicaciones Universidad Pontificia de Salamanca, Biblioteca Salmanticensis, Estudios 67, 1993).

Benito Rodríguez, José Antonio, La bula de cruzada en Indias (Madrid, Fundación Universitaria Española, 2002).

Bersani, F., Le fonti del Diritto canonico prima della codificazione, en Rivista di Diritto Ecclesiastico,10 (1917).

Boudinhon, A., De la codification du Droit canonique, en Le canoniste contemporain, 27 (1904); 28 (1905).

Calisse, C., La codificazione del Diritto canonico, en Rivista Internazionale di Scienze Sociali, 35 (1904).

Codex Iuris Canonicil Postulata Episcoporum/ in ordinem digestal al Rmo. P. Bernardino Klumper O. F. M./ Consultore/ Romael Typis Vaticanis/ $1905 / 283$ pp. ASV. CIC 1917, caja 4.

Donoso, Justo, Instituciones de Derecho canónico americano (Valparaíso, 1848-1849), I-II.

EDWIN Ferme, Brian, Introduzione alla storia delle fonti del Diritto canonico, I: Il Diritto antico fino al Decretum di Graciano (Roma, Pontificia Università Lateranense, 1998).

FANTAPPIÈ, Carlo, Chiesa romana e modernità giuridica, I: L'edificazione del sistema canonistico (1563-1903); II: Il Codex Iuris Canonici (1917) (Milano, Giuffrè, Per la storia del pensiero giuridico moderno 76, 2008).

García y García, Antonio, Historia del Derecho canónico, I: El primer milenio (Salamanca, 1967).

GaSPARri, Petrus (editor), Codicis Iuris Canonici Fontes, II: Romani Pontifices a. 18671917 , n. 545-713 (Typis Polyglottis Vaticanis, 1933).

GuZMÁn Brito, Alejandro, El origen y desarrollo de la idea de codificación del Derecho, en GuZmÁn Brito, Alejandro (editor), El Código Civil de Chile (1855-2005). Trabajos expuestos en el Congreso internacional celebrado para conmemorar su promulgación (Santiago, 3-6 de octubre de 2005) (Santiago, LexisNexis, 2007), pp. 43-99.

Mansi, J. D., Sacrorum conciliorum nova et amplissima collectio, Sacrosancti oecumenici Concilii Vaticani, 53.

LAMER, H., Zur Codification des canonischen Rechts (Freiburg Br., 1899).

Llobell, Joaquín - De León, Enrique - NaVArRete, Jesús, Il libro "De processibus" nella codificazione del 1917. Studi e documenti (Milano, Giuffré, 1999), I.

Retamal Fuentes, Fernando, Chilensia Pontificia. Monumenta Ecclesiae Chilensia (Santiago, Ediciones Universidad Católica de Chile, 2002), II, 2.

RuFInI, Francesco, La codificazione del Diritto ecclesiastico, en AA. VV., Studi di Diritto in onore di Vittorio Scialoja (Milano, 1905), II.

SAlinAS ARANEDA, Carlos, El primer aporte de los chilenos a la codificación del Derecho canónico de 1917: los "postulata episcoporum" acerca del matrimonio, en Historia, 41 (julio-diciembre 2008) 2, pp. 413-446.

Salinas ARANeda, Carlos, El primer aporte de los obispos chilenos a la codificación del Derecho canónico de 1917: los "postulata episcoporum", en Revista de Estudios Histórico-Jurídicos, 30 (2008).

Schema Codicis Iuris Canonici/ (Sub secreto pontificio/ Codex Iuris Canonicil cum notis/ 
Petri card. Gasparril Romae/ Typis Polyglottis Vaticanis/ MDCCCCXIV// Liber Quintus/ De iudiciis ecclesiasticis. ASV. CIC 1917, caja 70.

Vetulani, A., Codex Juris Canonici, en Dictionnaire de Droit Canonique (Paris, 1942), III.

Villien, A., Les reformes du Droit canonique et les "postulata" du concile du Vaticain, en Le canoniste contemporaine, 29 (1906); 30 (1907); 31 (1908). 